
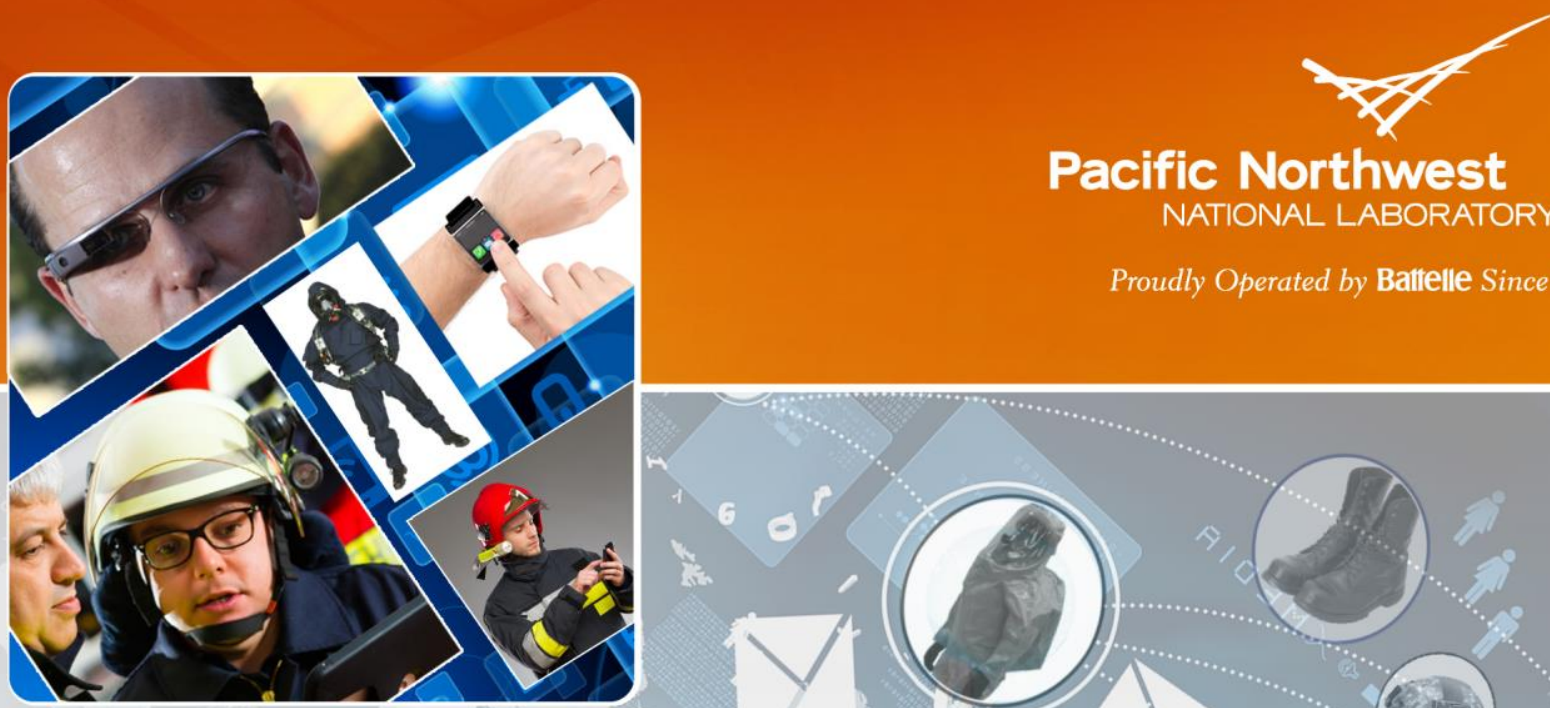

Pacific Northwest

NATIONAL LABORATORY

Proudly Operated by Baffelle Since 1965

Responder Techinology
Alert Monthly (January 2015)

\title{
February 2015
}

JF Upton

SL Stein
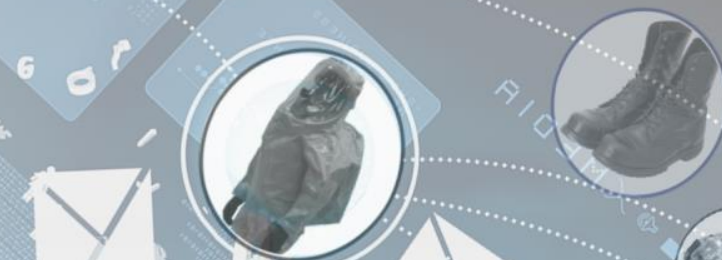

$\operatorname{lab}_{0}$

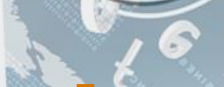




\title{
DISCLAIMER
}

This report was prepared as an account of work sponsored by an agency of the United States Government. Neither the United States Government nor any agency thereof, nor Battelle Memorial Institute, nor any of their employees, makes any warranty, express or implied, or assumes any legal liability or responsibility for the accuracy, completeness, or usefulness of any information, apparatus, product, or process disclosed, or represents that its use would not infringe privately owned rights. Reference herein to any specific commercial product, process, or service by trade name, trademark, manufacturer, or otherwise does not necessarily constitute or imply its endorsement, recommendation, or favoring by the United States Government or any agency thereof, or Battelle Memorial Institute. The views and opinions of authors expressed herein do not necessarily state or reflect those of the United States Government or any agency thereof.

\author{
PACIFIC NORTHWEST NATIONAL LABORATORY \\ operated by \\ BATTELLE \\ for the \\ UNITED STATES DEPARTMENT OF ENERGY \\ under Contract DE-AC05-76RL01830
}

Printed in the United States of America
Available to DOE and DOE contractors from the Office of Scientific and Technical Information, P.O. Box 62, Oak Ridge, TN 37831-0062; ph: (865) 576-8401 fax: $(865) 576-5728$
email: reports $a$ adonis.osti.gov
Available to the public from the National Technical Information Service 5301 Shawnee Rd., Alexandria, VA 22312 ph: (800) 553-NTIS (6847) email: orders@ntis.gov <http://www.ntis.gov/about/form.aspx> Online ordering: http://www.ntis.gov




\section{Responder Technology Alert Monthly (January 2015)}

JF Upton

SL Stein

February 2015

Prepared for the Department of Homeland Security Science and Technology Directorate under Contract HSHQPM-14-X-00058.

Pacific Northwest National Laboratory Richland, Washington 99352 

PNNL RTA Monthly Report - January 2015

\section{Acronyms and Abbreviations}

GNSS

GPS

NFC

PNNL

RFID

RTA

SCBA global national satellite system

global positioning system

near-field communications

Pacific Northwest National Laboratory

radiofrequency identification

Responder Technology Alliance

self-contained breathing apparatus 


\section{Contents}

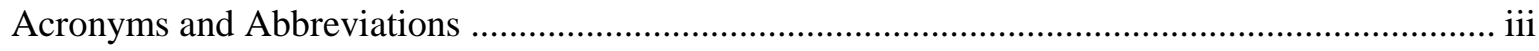

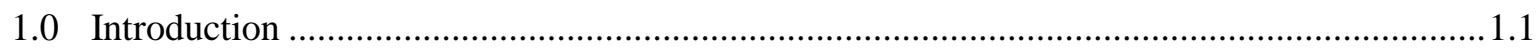

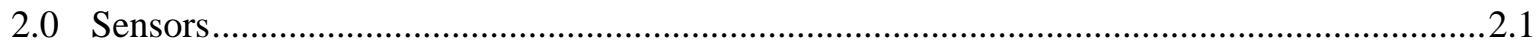

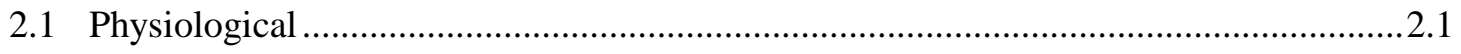

2.1.1 Blackbox Biometrics: Linx Impact Assessment System ..................................2.1

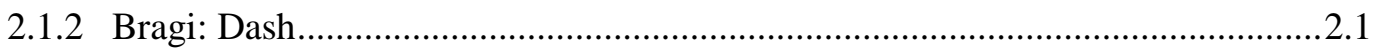

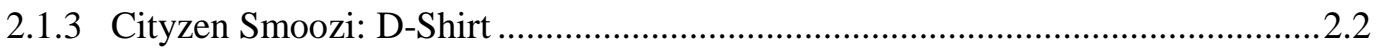

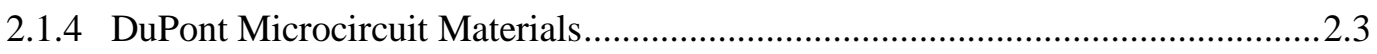

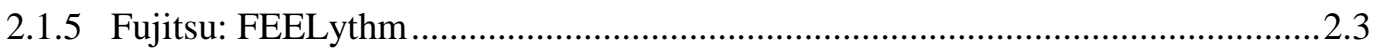

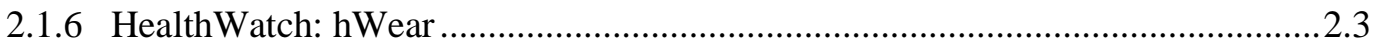

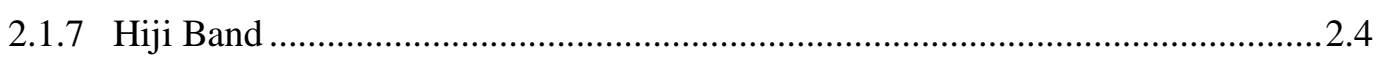

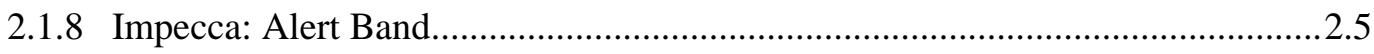

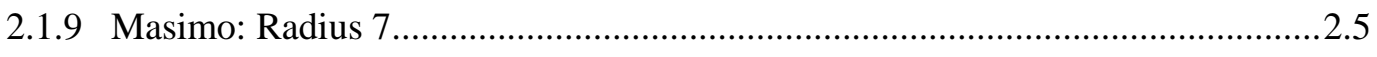

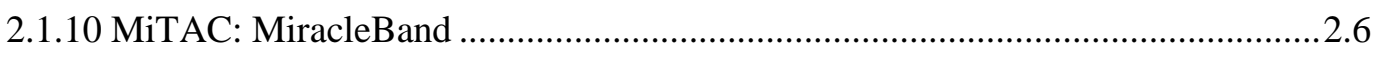

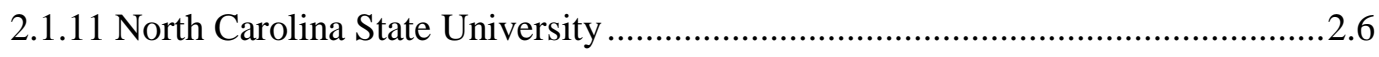

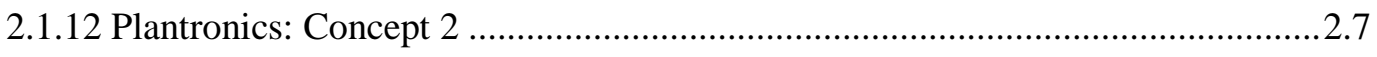

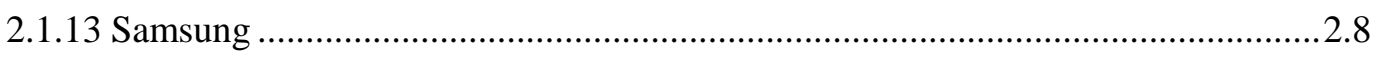

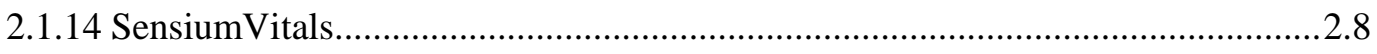

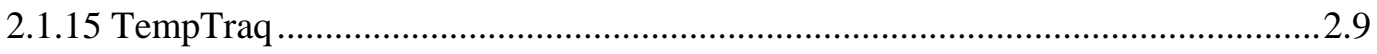

2.1.16 University of California San Diego Center for Wearable Sensors .........................2.9

2.1.17 University of Maryland, Microsoft: SWARM .................................................2.10

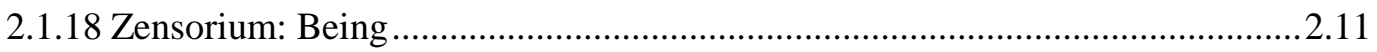

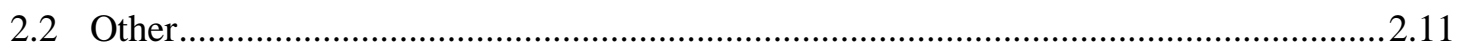

2.2.1 Amulet Corp: Scarab …................................................................................ 2.11

2.2.2 John Knollmeyer, Timotius Sitorus, Kushagra Pundeer (individuals) ...............2.12

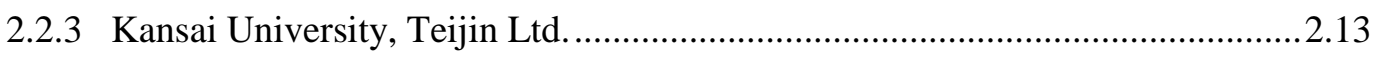

2.2.4 Nottingham Trent University's Advanced Textiles Research Group.................2.13

2.2.5 PNI Sensor Corp: SENtrode ........................................................................... 2.13

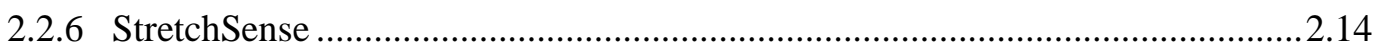

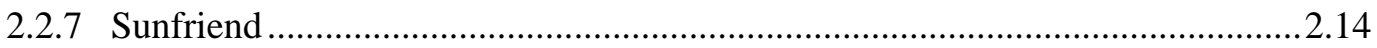

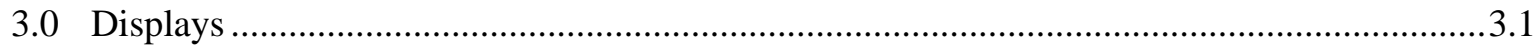

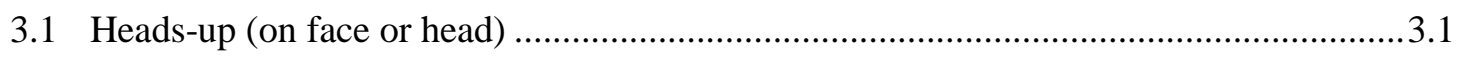

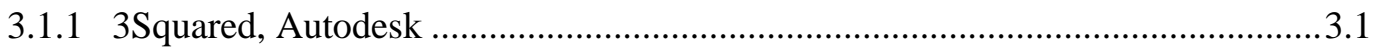

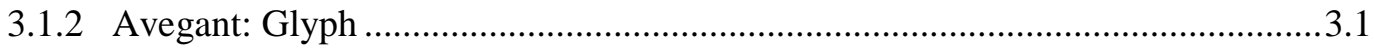

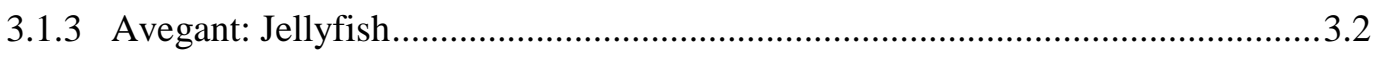

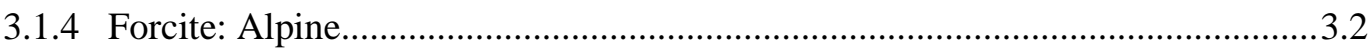




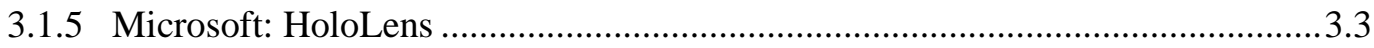

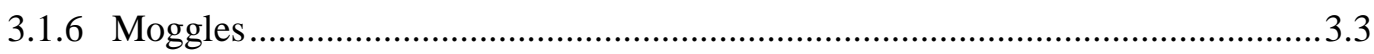

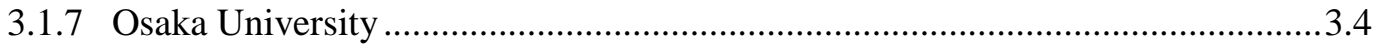

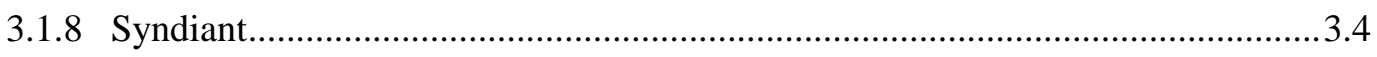

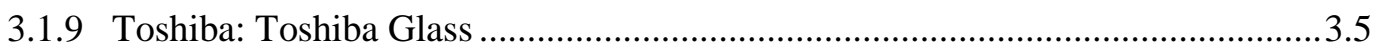

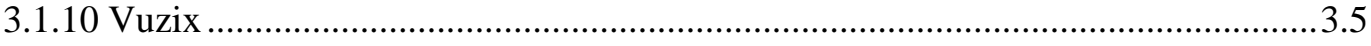

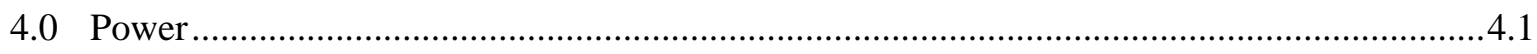

4.1 Self-powering (Harvesters) ................................................................................... 4.1

4.1.1 Hahn-Schickard-Gesellschaft Institute for Micromachining and Information

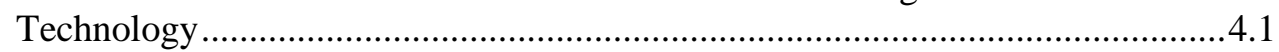

4.1.2 Korea Advanced Institute of Science and Technology TEGway .......................... 4.1

4.1.3 Korea Advanced Institute of Science and Technology: ZnO ...............................4.2

4.1.4 Korea Institute of Science and Technology, et al.............................................. 4.2

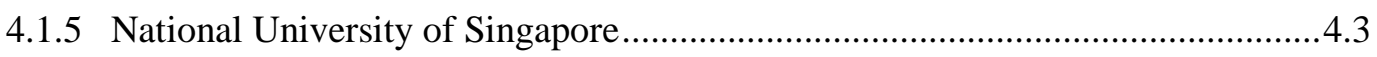

4.1.6 Sogang University Micro \& Nano Engineering Laboratory (MNELAB) .............4.4

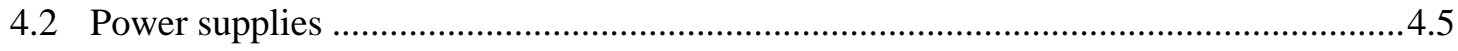

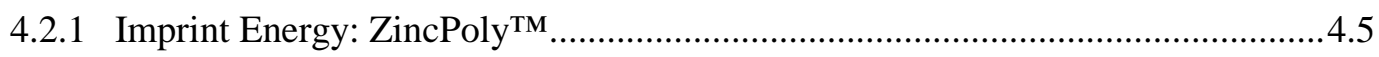

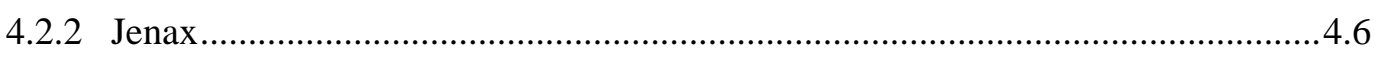

4.2.3 Rice University .................................................................................... 4.6

4.2.4 Toes Opto-Mechatronics ............................................................................... 4.7

4.2.5 University of Central Florida ….................................................................... 4.7

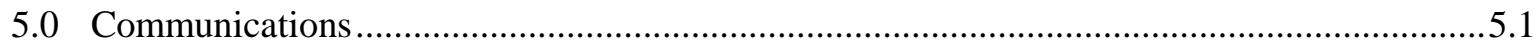

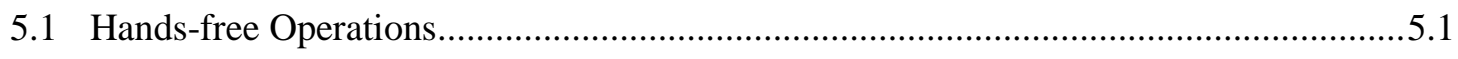

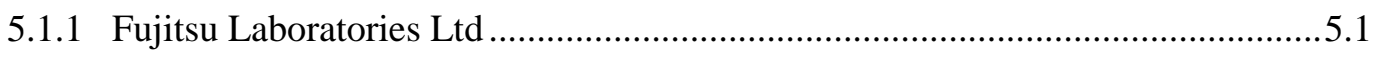

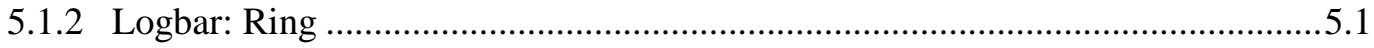

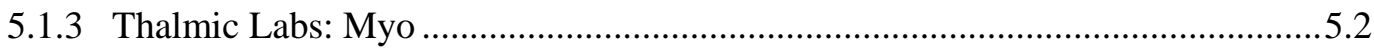

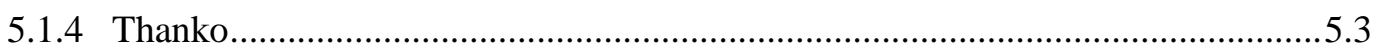

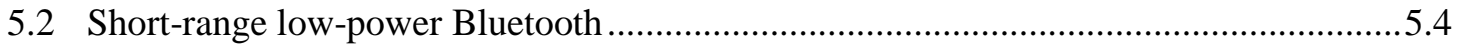

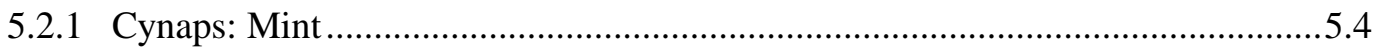

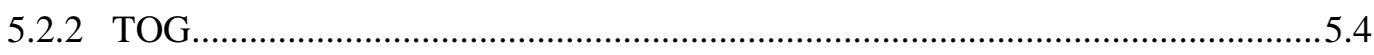

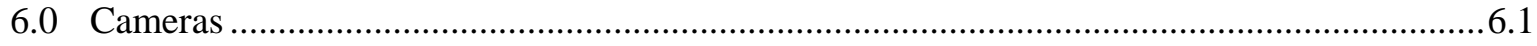

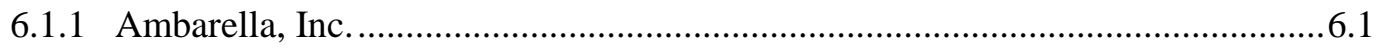

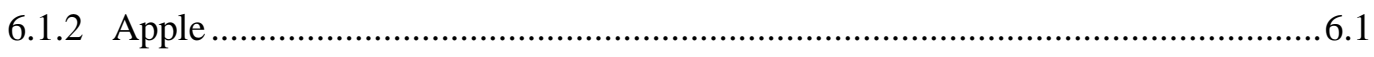

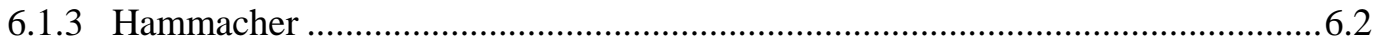

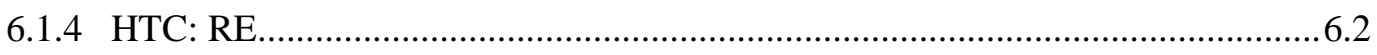

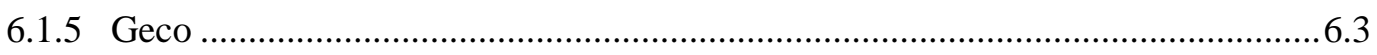

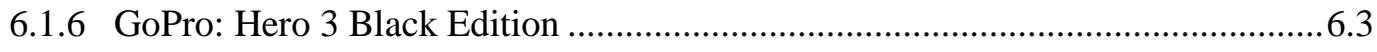

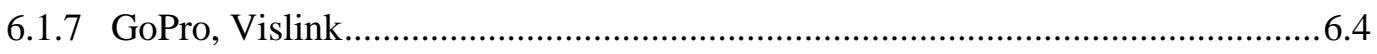

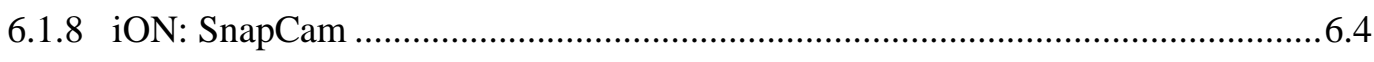




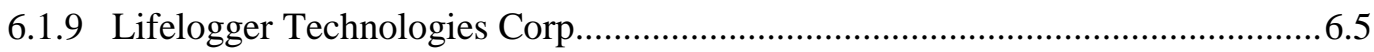

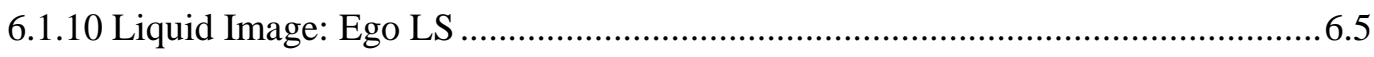

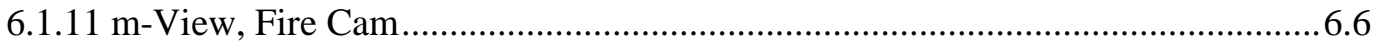

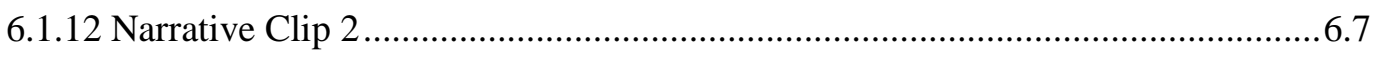

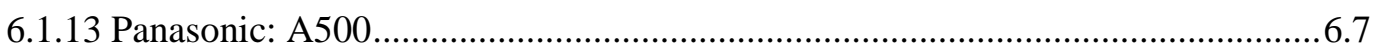

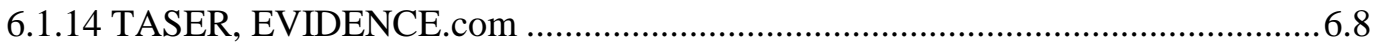

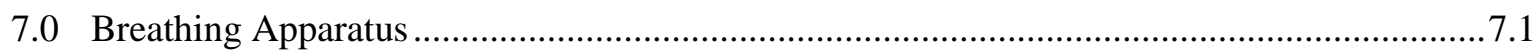

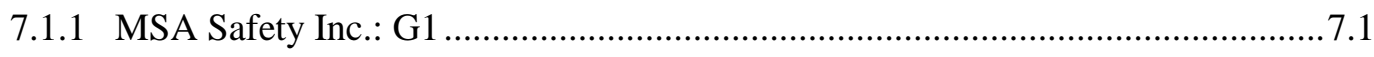

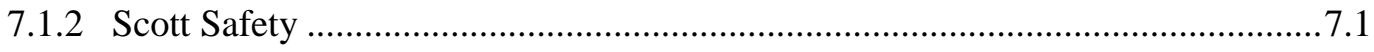

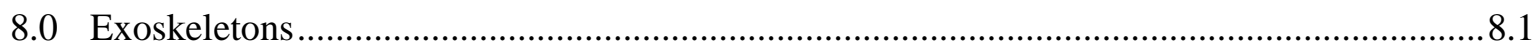

8.1 .1 Ritsumeikan University ............................................................................ 8.1

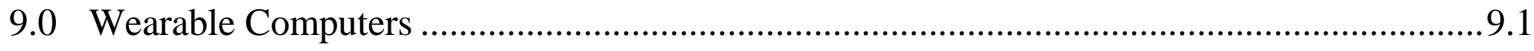

9.1.1 Arduboy: Ö Bluetooth Ring …................................................................. 9.1

9.1.1 Human Interactive Reliable Integrated Smartwatch (HIRIS) .............................. 9.1

9.1.2 XOEye Technology, Vuzix ....................................................................... 9.2

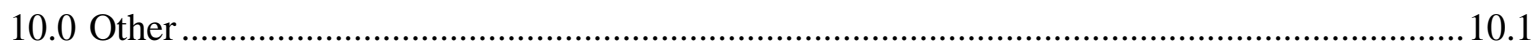

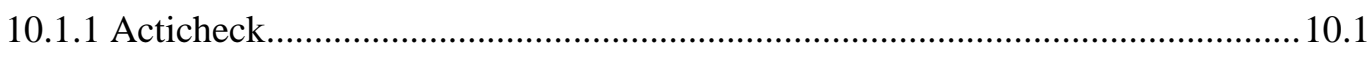

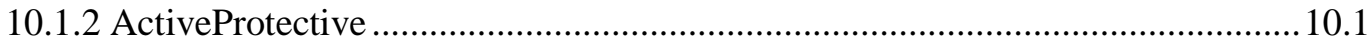

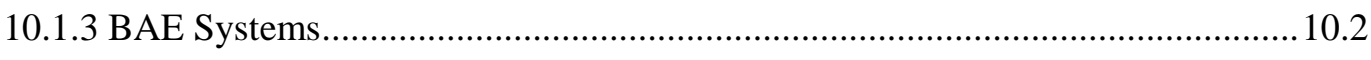

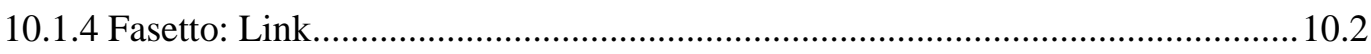

10.1.5 Globalfoundires, Linear Dimensions Semiconductor Inc............................... 10.3

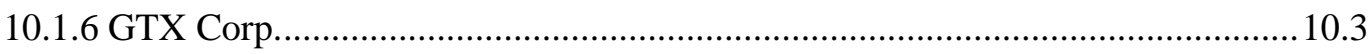

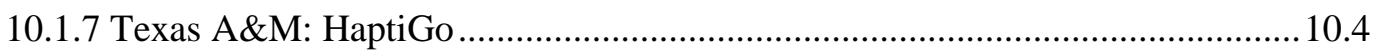

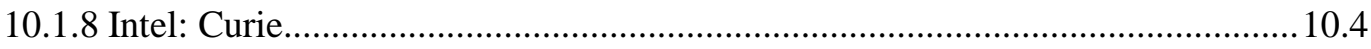

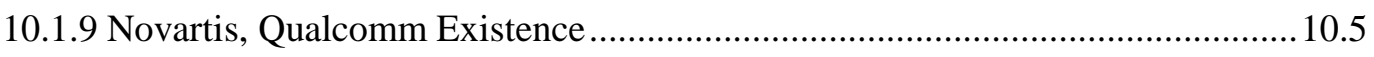

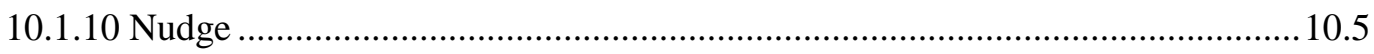

10.1.11 Quantum Functional Semiconductor Research Center................................... 10.5

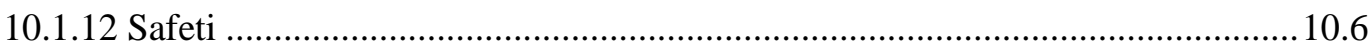

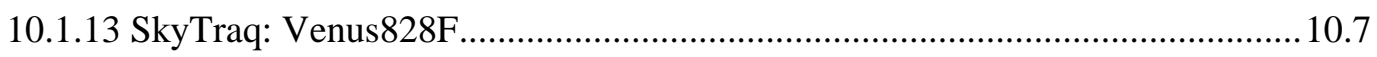

10.1.14 Stanford University ................................................................................. 10.7

10.1.15 Sussex Sensor Technology Research Centre...............................................10.8

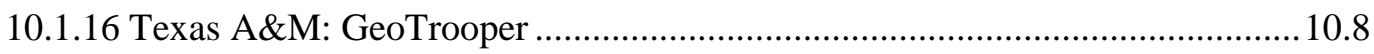

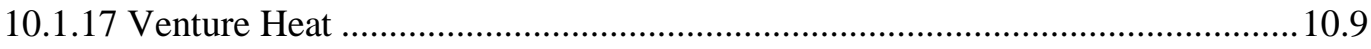

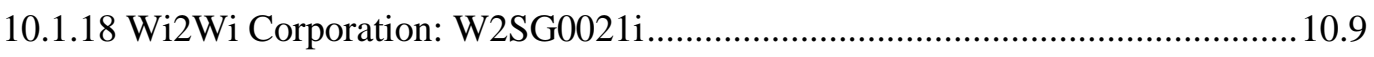

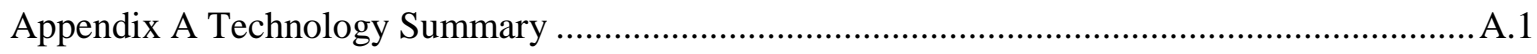


PNNL RTA Monthly Report - January 2015

\subsection{Introduction}

The Pacific Northwest National Laboratory (PNNL) is supporting the Department of Homeland Security (DHS) to advance technologies to enhance responder health and address complex and changing threat environments. The DHS Science and Technologies First Responders Group established the Responder Technology Alliance (RTA) to accelerate the development of solutions to first responder needs and requirements by identifying, analyzing, and recommending solutions that improve responder safety, enhance their ability to save lives, and minimize property loss. The end goal is for RTA to develop and implement strategies that will make effective solutions available to first responders.

As part of technology foraging for the RTA, this report summarizes technologies that are relevant in the area of "wearables," with the potential for use by first responders. The content was collected over the previous month(s) and reproduced from a general Internet search using the term wearables. Additional information is available at the websites provided. The content is organized by technology function including:

- Sensors - Devices that detect physiological, particle, and chemical activity

- Displays - Heads-up and body-worn visual displays

- Power - Wearable power systems including chargers, batteries, self-powering or harvesting technologies, and power supplies

- Integrated Communications - Voice and data communications systems utilizing Bluetooth, wireless, hands-free, ergonomically optimized systems, noise-filtering digital speakers or microphones, etc.

- Cameras - Body-worn photo and video cameras

- Breathing Apparatus - Wearable air supply and monitoring devices

- Exoskeletons - Whole or partial body suit that enhances mobility and physical performance

- Wearable Computers - Body-worn data processing devices

- General - Miscellaneous technologies as well as emerging trends or recent advances in the field of wearables.

This report is not meant to be an exhaustive list nor an endorsement of any technology described herein. Rather, it is meant to provide useful information about current developments in the areas wearable technology.

A spreadsheet summarizing these technologies is available in Appendix A. For an electronic copy, contact Jaki Upton at jaki.upton@pnnl.gov. 

PNNL RTA Monthly Report - January 2015

Sensors

\subsection{Sensors}

\subsection{Physiological}

\subsubsection{Blackbox Biometrics: Linx Impact Assessment System}

Technology name: Linx Impact Assessment System (IAS)

Description: Linx IAS features an accelerometer and a gyroscope and can be worn on its own or in a helmet to monitor impact and head injuries. Upon impact, "the sensor sends an alert to the app - up to 300 foot range - with a color-coded notification of the potential injury and severity of the impact." The app tracks and allows the user to analyze the data as well as share it with medical professionals.

Status: Soon to be released - Anticipated March 2015

Funding:

Product link: $\underline{\text { http://linxias.com }}$

Source: Headband sensor warns of sports injuries in real time http://mashable.com/2015/01/04/linx-ias-ces/

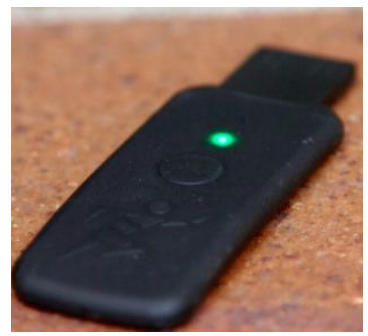

Photo Source: http://mashable.com/2015/01/04/linx-ias-ces/

\subsubsection{Bragi: Dash}

Technology name: Dash smart earbuds

Description: Dash is an ear-worn device that measures activity including speed, distance, steps, and calorie burn. Dash comprises 3-axis accelerometer, gyroscope, magnetometer, 4GB flash drive, as well as two LEDs that emit low intensity red and infrared light into the skin to measure heart rate, oxygen saturation, and temperature. Additionally, the device employs high-resolution optical touch sensors to recognize gestures to control the device.

Status: Evolving - currently in the evaluation phase, projected to ship in May 2015.

\section{Funding:}

Product link: http://store.bragi.com/

Source: Dash kicks off the Hearables market, a new frontier in the wearable industry 
http://www.talkandroid.com/233600-dash-kicks-off-the-hearables-market-a-new-frontier-in-the-wearableindustry/

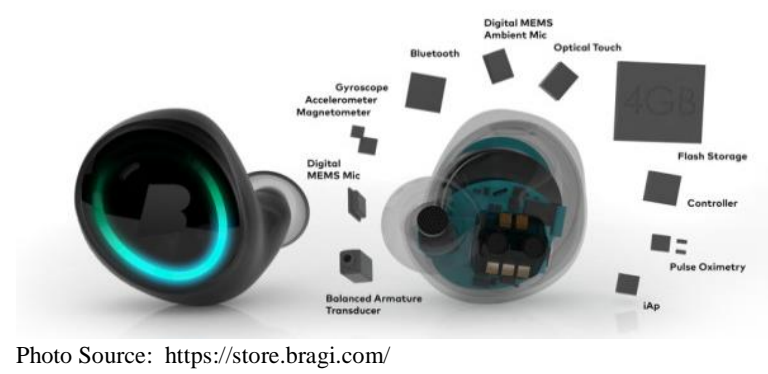

\subsubsection{Cityzen Smoozi: D-Shirt}

Technology name: Digital Shirt (D-Shirt)

Description: D-Shirt is a smart garment with sensors embedded in the fabric that measure heart rate, temperature, speed, and distance and provide that information to the user. Cityzen has produced bike shorts with the technology and signed with Asics to produce a shirt for jogging. The designer is considering alternative needs for smart fabrics like measuring air quality.

Status: Evolving - presented prototype at Consumer Electronics Symposium.

\section{Funding:}

Product link: http://www.smartsensing.fr/en

Source: The Cityzen Smoozi D-Shirt Measures Heart Rate and Body Temperature, So They Can Actually Improve (Or Save) Your Life http://www.bustle.com/articles/57634-the-cityzen-smoozi-d-shirt-measures-heart-rate-and-bodytemperature-so-they-can-actually-improve-or

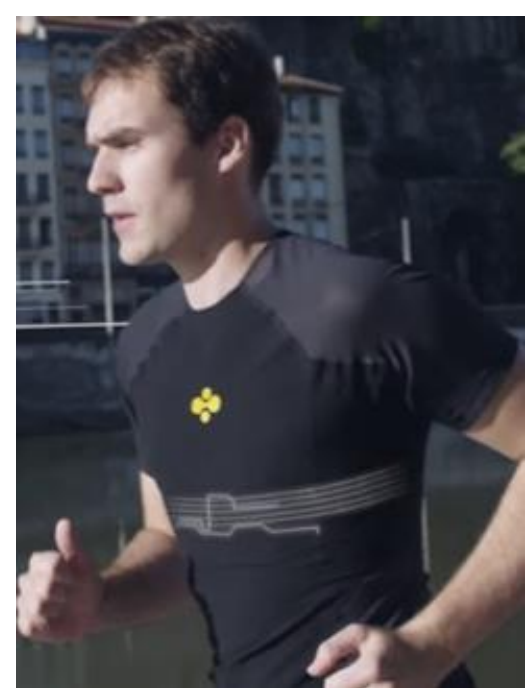

Photo Source: http://www.bustle.com/articles/57634-the-cityzen-smoozi-d-shirt-measures-heart-rate-and-body-temperature-so-they-can-actually-improveor/image/57634 


\subsubsection{DuPont Microcircuit Materials}

Technology name: Stretchable, conductive ink materials

Description: DuPont is producing a shirt made of "stretchable, washable conductive ink materials" that monitor oxygen levels, heart rate, and temperature. The material is anticipated to have other applications including glucose test strips and antennas.

Status: Evolving

Funding:

Product link: http://www.dupont.com/products-and-services/electronic-electrical-materials/printedelectronics.html

Source: DuPont MCM enables Wearable Technology thanks to Stretchable http://www.printedelectronicsworld.com/articles/7231/dupont-mcm-enables-wearable-technology-thanksto-stretchable-inks

\subsubsection{Fujitsu: FEELythm}

\section{Technology name: Vehicle ICT FEELythm}

Description: The device detects a driver's alertness via a sensor attached to the earlobe, and the data can be shared with other devices, such as a fleet management system, to monitor the driver's condition. The device features a 5-day battery life, and monitors several vital signs including pulse rate and the autonomic nervous system; the data is reported to a device worn around the neck and can be used to alert the driver. The device uses Fujitsu proprietary algorithm to interpret the data to gauge drowsiness and notify the driver and network, such as a fleet manager.

Status: Evolving - to be available for sale in Japan in February 2015

\section{Funding:}

Product link: http://www.fujitsu.com/global/about/resources/news/press-releases/2015/0119-02.html

Source: Fujitsu: Launches FEELythm, a Wearable Sensor That Promotes Safer Driving http://www.4-traders.com/FUJITSU-LTD-6492460/news/Fujitsu--Launches-FEELythm-a-WearableSensor-That-Promotes-Safer-Driving-19727547/

\subsubsection{HealthWatch: hWear}

Technology name: hWear ${ }^{\mathrm{TM}}$

Description: hWear is machine-washable sensing garments that feature 3 to 15 lead ECG sensors to continuously monitor activity (heart rate, blood pressure, cardiac irregularities and other vital signs) that is uploaded to the receiver or a doctor via Bluetooth or Wi-Fi. The device will also alert the users in the case that abnormalities are detected. 
PNNL RTA Monthly Report - January 2015

Sensors

Status: Evolving

\section{Funding:}

Product link: http://www.personal-healthwatch.com/

Source: myNEXUS Active Telehealth

http://unitedwithisrael.org/israeli-company-creates-wearable-technology-that-will-save-lives/

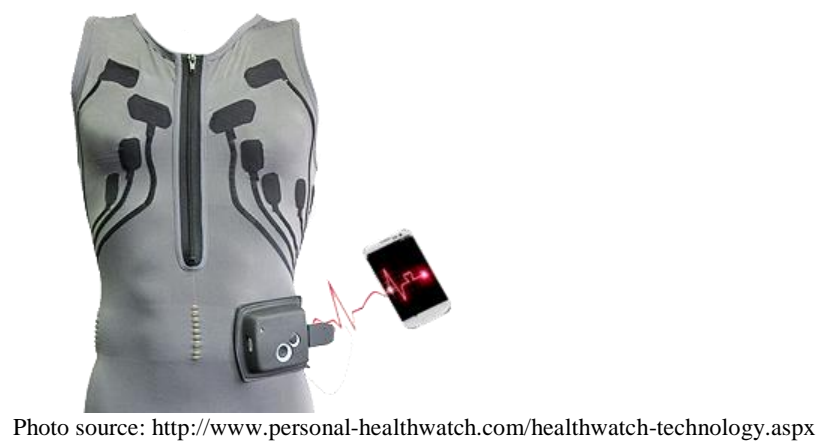

\subsubsection{Hiji Band}

Technology name: Hiji Band

Description: The headband comprises sensors that can track impact data, including direction, location and speed, and report the data to a mobile app, which can also produce images, graphs, and text to help the user interpret the data. The device "facilitates long-term data collection that allows teams to compile a 'lifetime' record of all notable head impacts that the player has received" and is anticipated to help players and coaches understand impacts and treatment.

Status: Evolving

Funding: Crowdfunding

Product link: http://hijiband.com/

Source: The Hiji Band - Wearable Technology to Detect Concussions

https://www.kickstarter.com/projects/73591272/the-hiji-band-wearable-technology-to-detect-concus 
PNNL RTA Monthly Report - January 2015

Sensors

\section{Product Features}

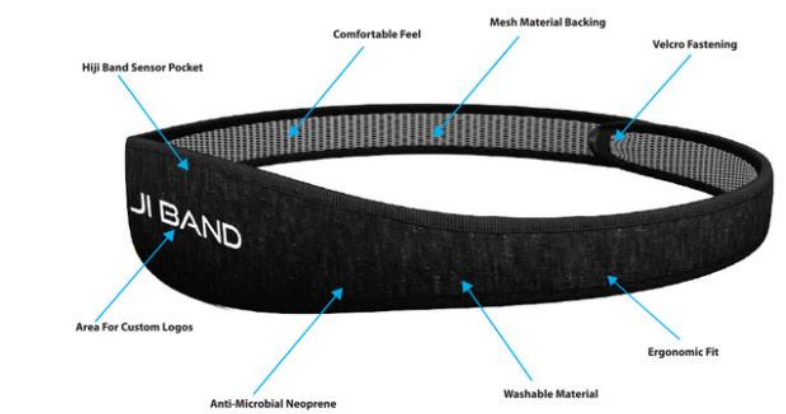

Photo Source: https://www.kickstarter.com/projects/73591272/the-hiji-band-wearable-technology-to-detect-concus

\subsubsection{Impecca: Alert Band}

Technology name: Alert Band

Description: The Alert Band is an "early warning Bluetooth fatigue detector band" intended to help longdistance drivers stay safe and awake on the road. The device attaches to a driver's forehead where it analyzes brainwaves to measure alertness and sends real-time alerts to the driver's smartphone to wake the driver as well as notifications to the driver's network. The device uses a 0-100 scale to rate the driver's alertness, with $>80$ indicating "dangerous." The device features a 20 -hour battery life.

Status: Soon to be released - Expected May 2015

\section{Funding:}

Product link: $\underline{w w w . i m p e c c a . c o m}$

Source: Impecca Introduces Wearable Early Warning Fatigue Detector for Drivers http://www.emsworld.com/news/12031515/wearable-early-warning-fatigue-detector-for-drivers

\subsubsection{Masimo: Radius 7}

\section{Technology name: Radius 7}

Description: The device attaches to a hospital patient's arm and allows them to move freely while providing necessary, continuous monitoring to detect changes in the patient's condition. Radius 7 is the "only patient monitoring and connectivity platform that uses Masimo's 'breakthrough' rainbow Signal Extraction Technology (SET), which measures oxygen saturation (SpO2) and pulse rate, respiration rate and provides noninvasive and continuous haemoglobin $(\mathrm{SpHb})$ monitoring." The device includes two rechargeable modules and a 12- hour battery life.

Status: Evolving

\section{Funding:}

Product link: http://www.masimo.com/root/radius-7.htm 
PNNL RTA Monthly Report - January 2015

Sensors

Source: Masimo's Radius-7 provides wearable, noninvasive monitoring http://trends.medicalexpo.com/products/masimos-radius-7-provides-wearable-noninvasive-monitoring/

\subsubsection{MiTAC: MiracleBand}

Technology name: MiracleBand

Description: MiracleBand allows a user to track and analyze physiological conditions including sleep patterns and exercise, as well as "physiological age, stress, energy and the balance of the autonomic nervous system." The device connects with smart devices and cloud services and features "industry-leading 2minute ECG detection through NASA EMD technology and precise physical health index analysis" as well as "breathing training to reduce stress and recover energy via smartphone app." The device's "ECG analysis and health indexes have been verified through consultation with cardiology and psychiatry professionals, as well as collaboration with medical professors and research teams from top universities in Taiwan and abroad."

Status: Evolving

\section{Funding:}

Product link: http://www.mitac.com/

Source: MiTAC Announces MiracleBand, the Wearable Wellness Solution at CES 2015

http://www.prnewswire.com/news-releases/mitac-announces-miracleband-the-wearable-wellnesssolution-at-ces-2015-300015759.html

\subsubsection{North Carolina State University}

Technology name: Wearable sensor

Description: The device uses silver nanowires which are inlaid in a stretchable polymer to monitor electrophysiological signals, such as electrocardiography (EKG) or electromyography (EMG). This "dry" device delivers accuracy comparable to "wet electrodes" used in hospitals but can support longer-term monitoring and improved accuracy when a patient is moving.

Status: Evolving

Funding:

Research link: http://dx.doi.org/doi:10.1039/C4RA15101A

Source: Wearable nanowire sensor clears path to long-term EKG, EMG monitoring http://www.nanowerk.com/nanotechnology-news/newsid=38758.php 


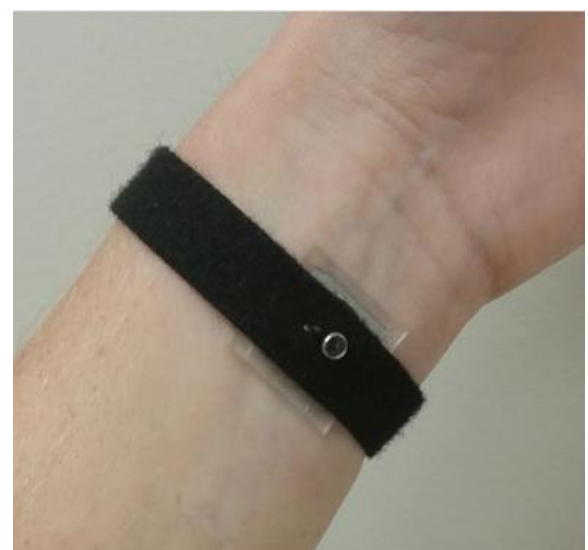

Photo source: http://www.nanowerk.com/nanotechnology-news/newsid=38758.php

\subsubsection{Plantronics: Concept 2}

Technology name: Concept 2

Description: An ear-worn device that offers a sensor and motion-tracking capabilities as well as enhanced video call capabilities. The device features sensors for "compass heading, angular velocity, and acceleration" as well as "software development kits for mobile and desktop to help third-party developers concoct real-world apps that take advantage of these earpiece extras." Similar to Plantronic's Voyager Legend device, Concept 2 can track head and body movements in 3-D space. The can be used to wirelessly unlock a door using voice commands, wirelessly connect to a smart device in a remote location and "a telepresence robot."

Status: Evolving

\section{Funding:}

Product link: http://www.plantronics.com/us/

Source: Who Needs a Wristband? Plantronics Puts Wearable Tech in Your Ear http://www.thestreet.com/story/13000430/1/who-needs-a-wristband-plantronics-puts-wearable-tech-inyour-ear.html

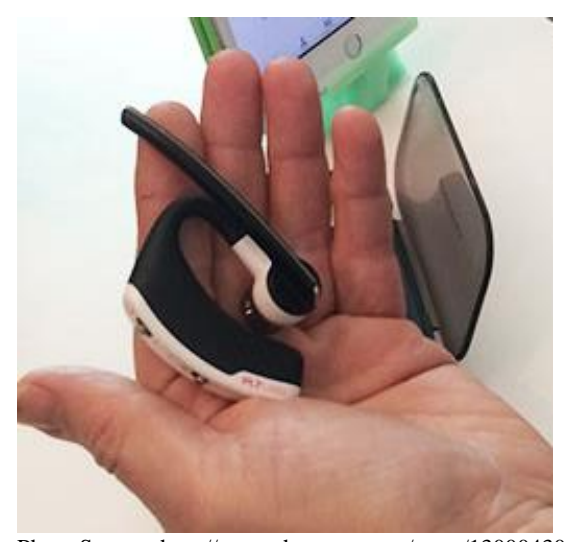

Photo Source: http://www.thestreet.com/story/13000430/1/who-needs-a-wristband-plantronics-puts-wearable-tech-in-your-ear.html 


\subsubsection{Samsung}

Technology name: Early Detection Sensor \& Algorithm Package (EDSAP)

Description: Sensors on a headset "collect and transmit brainwave data to a mobile app, where the algorithm analyzes the brainwaves and ultimately determines the likelihood of a stroke, all within a 60second time span." The device has anticipated applications to help analyze neurological health, such as stress, anxiety, and sleep patterns.

Status: Evolving

\section{Funding:}

Product link: http://global.samsungtomorrow.com/c-lab-engineers-developing-wearable-health-sensorfor-stroke-detection/

Source: Samsung Working On New Wearable To Detect Strokes

https://www.geeky-gadgets.com/samsung-working-on-new-wearable-to-detect-strokes-22-01-2015/

\subsubsection{SensiumVitals}

Technology name: SensiumVitals

Description: SensiumVitals is a "light-weight, wearable, wireless single patient use patch" that takes a patient's vital signs (heart rate, respiration, temperature) every two minutes and can communicate the information to the patient's physician. It is the "the first single patient use product aimed at the general floor and emergency room of hospitals to have received FDA 510(k) clearance and CE marking."

Status: Evolving - available in the UK.

\section{Funding:}

\section{Product link:}

Source: SensiumVitals® system: Wireless monitoring of vital signs http://www.sensium-healthcare.com/sensiumvitals\%C2\%AE-system\#.VL12Jk0cRmM 
PNNL RTA Monthly Report - January 2015

Sensors

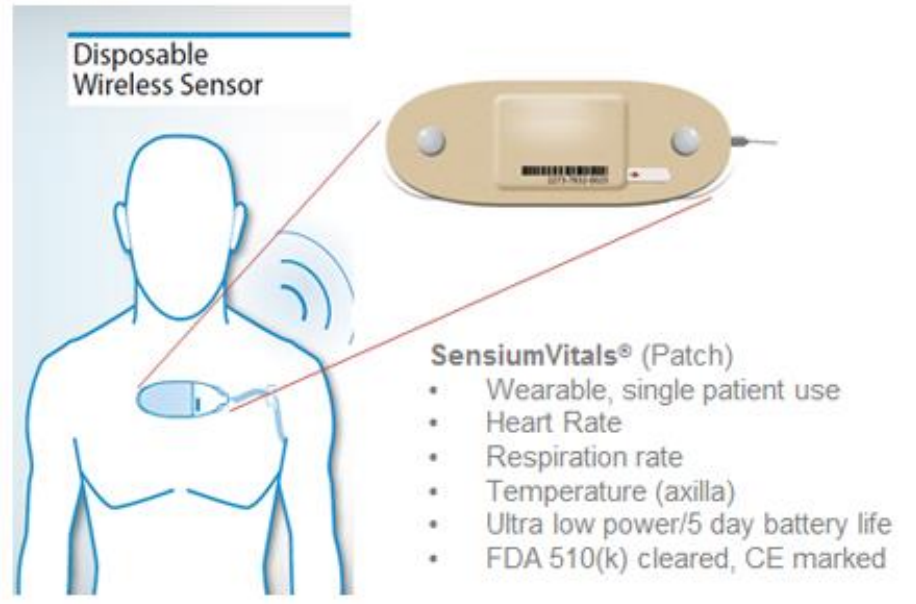

Photo Source: http://www.sensium-healthcare.com/sensiumvitals\%C2\%AE\#.VNUWhU0cSgw

\subsubsection{TempTraq}

Technology name: Temptraq wearable thermometer patch

Description: Temptraq is a wearable soft-patch thermometer that allows a user to track body temperature for up to 24 hours via Bluetooth and a smartphone app. It features a color-coded light display to indicate severity of the fever.

Status: Evolving

\section{Funding:}

Product link: http://www.temptraq.com/

Source: CES 2015: TempTraq Wearable Bluetooth Thermometer http://www.tuaw.com/2015/01/04/ces-2015-temptraq-wearable-bluetooth-thermometer/

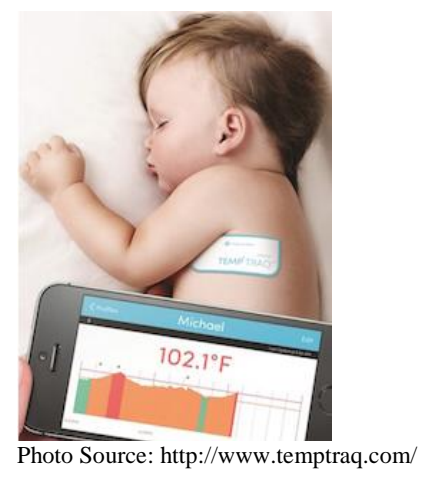

\subsubsection{University of California San Diego Center for Wearable Sensors}

Technology name: Paper-based "tattoo" glucose monitor 
Description: This "paper-based temporary tattoo" adheres to the skin and measures a user's glucose. It also uses electrodes to zap skin to indicate levels that are out of the intended range. . The device features "a sensor built into the tattoo [that] measures the strength of the electrical charge produced by the glucose to determine a person's overall glucose levels." The tattoos cost a few cents, compared to the average \$2 for the commonly used strips. Researchers have shown that the tattoos may have other uses such as measuring physical stress or electrolyte imbalance

Status: Evolving

\section{Funding:}

Product link: http://www.jacobsschool.ucsd.edu/news/news_releases/release.sfe?id=1691

Source: Forget Needles: For Diabetics, This Temporary Tattoo Tracks Blood Sugar Without Pain http://www.fastcoexist.com/3041258/forget-needles-for-diabetics-this-temporary-tattoo-tracks-bloodsugar-without-pain

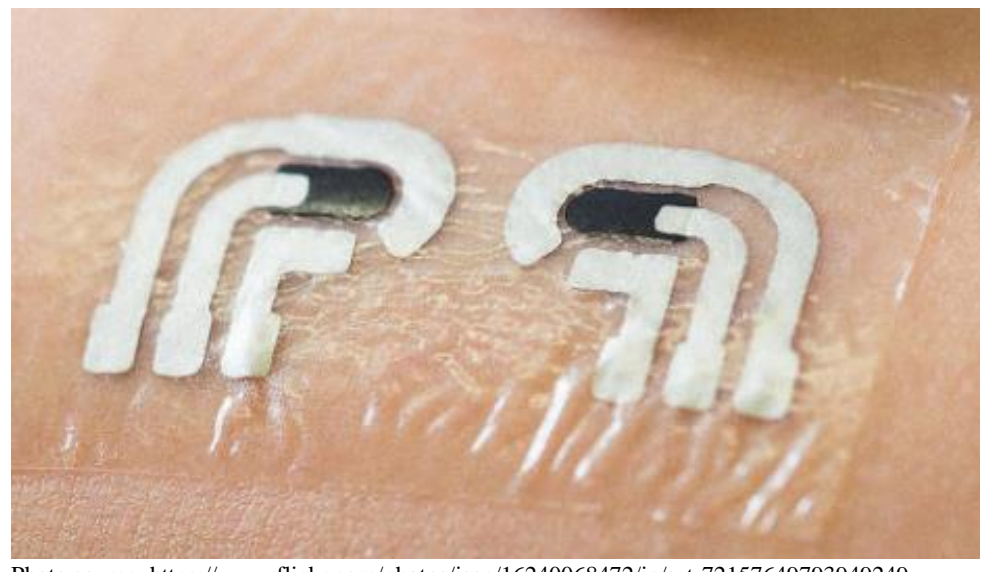

Photo source: https://www.flickr.com/photos/jsoe/16240068472/in/set-72157649793949249

\subsubsection{University of Maryland, Microsoft: SWARM}

Technology name: SWARM smart scarf

Description: SWARM is designed to help users "reflect on their own emotional state, modify their affect, and interpret the emotional states of others." Conductive fabric circuity in this "smart scarf" comprises a series of modules that can heat up and vibrate and are controlled via smart phone over Bluetooth.

Status: Evolving

\section{Funding:}

\section{Product link:}

Source: SWARM: An Actuated Wearable for Mediating Affect http://research.microsoft.com/pubs/238353/swarm.pdf 
PNNL RTA Monthly Report - January 2015

Sensors
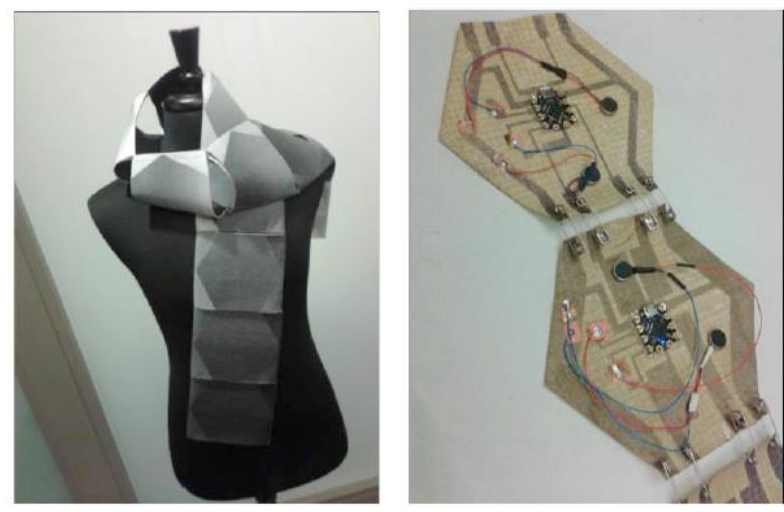

Figure 1. Our modular cotton scarf houses canvas modules

with conductive fabric circuitry designed to control heat, vibration, and audio actuations.

Photo Source: http://research.microsoft.com/pubs/238353/swarm.pdf

\subsubsection{Zensorium: Being}

Technology name: Being activity tracker

Description: Being is a smart wristband (or clip) that can track NREM and REM sleep, heart rate, steps, calorie burn, distance, speed, and mood (Distress, Excited, Normal and Calm), which it figures by measuring heart rate and blood pressure. The device is reported to have a battery life of 2-3 days and an OLED touchscreen display.

Status: Evolving

Funding:

Product link: http://www.zensorium.com/being

Source: Zensorium's 'Being' is a fitness wearable that promises to track your mood as well http://www.engadget.com/2015/01/04/zensorium-being/

\subsection{Other}

\subsubsection{Amulet Corp: Scarab}

Technology name: Scarab wearable sensor platform

Description: Scarab allows the user to continuously monitor their environment and communicate "local conditions and hidden dangers" via smartphone to the web and the user's contacts. The device utilizes mobile apps, an online mapping service to play sensor impressions (i.e., Google Maps), and the user's selected community of contacts. The app collects data over time and notifies the user of dangers of longterm buildup. The app also overlays data on a map and allows the user to see where they have traveled and the relative Scarab readings, creating a map of areas of concerns. The app can supply alerts and help users analyze their environment conditions. Scarab includes the following sensors: Ambient Light sensor, 
UV Index sensor, Gamma detector, Thermometer, Relative Humidity sensor, Noise Level detection circuit, Digital Output Barometer, Gyroscope, 3D Magnetometer, 3D Accelerometer, GPS Module, Three axis magnetic field sensor, Liquid Petroleum Gas detector, Carbon Monoxide detector, Ozone detector, Nitrogen Dioxide detector. The data can be shared with other Scarab users.

Status: Evolving

Funding: Crowdfunding

Product link: http://amuletcorp.com/

Source: Scarab: See the world around you with new eyes https://www.kickstarter.com/projects/1043963391/scarab-see-the-world-around-you-with-new-eyes

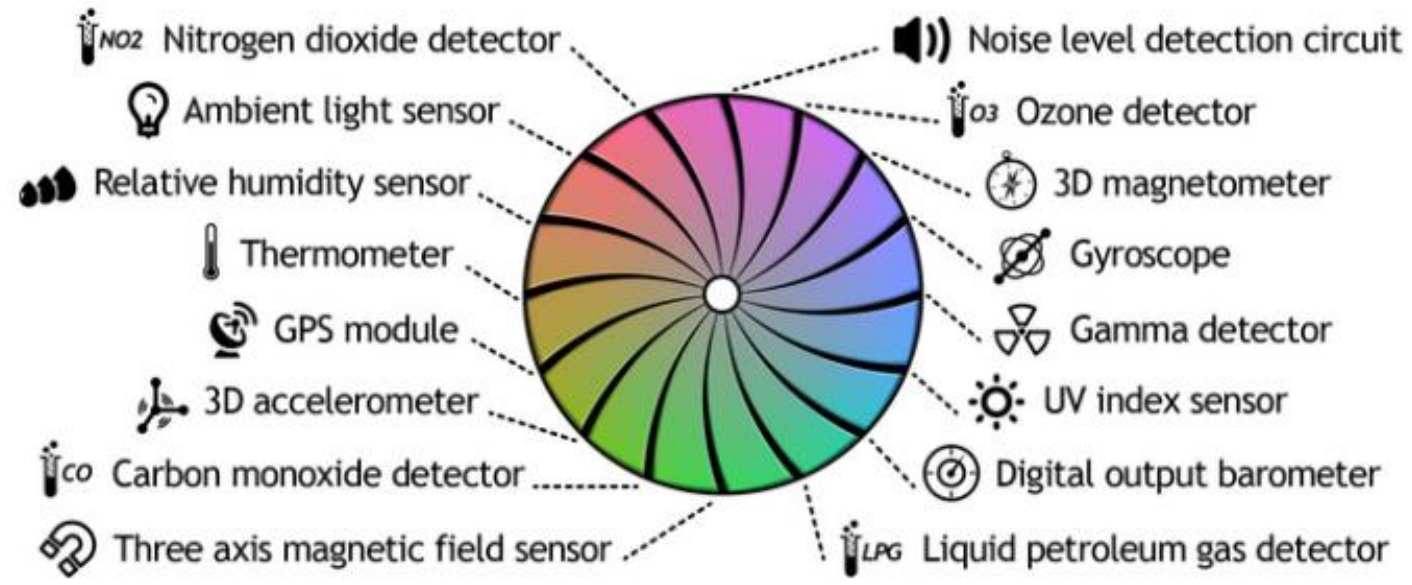

Photo Source: http://amuletcorp.com/

\subsubsection{John Knollmeyer, Timotius Sitorus, Kushagra Pundeer (individuals)}

Technology name: Ultrasonic obstacle detector

Description: This device is a "head-mounted ultrasonic rangefinder with variable feedback for obstacle detection" that gives a user with limited or no vision the ability to detect the distance and direction of obstructions, giving them the ability to determine obstructions in their environment without having to physically feel them. Vibrations notify the user when an object is in the path of the ultrasonic sensor. Different vibrations or feedback responses denote the distance of the obstacle. The device is mounted on eyeglasses so the user can rotate their head to scan for objects in their surroundings.

Status: Evolving

\section{Funding:}

\section{Product link:}

Source: Wearable Ultrasonic Obstacle Detector http://challengepost.com/software/wearable-ultrasonic-obstacle-detector 
PNNL RTA Monthly Report - January 2015

\subsubsection{Kansai University, Teijin Ltd.}

Technology name: Polylactic acid (PLA) fiber- and carbon-fiber-based piezoelectric fabrics

Description: The fabrics combine polymer and textile technologies and piezoelectric materials (a piezoelectric poly-L-lactic acid (PLLA) and carbon fiber electrode) to produce a flexible fabric that can detect complex movements. The researchers created plain, twill, and satin weave versions with a goal for "ideal weaves and knits for fabric applications that enable elaborate human actions to be monitored simply via clothing worn by people" This wearable piezoelectric fabric is a new application of the flexible, transparent piezoelectric that Kansai University and Teijin developed in 2012.

Status: Evolving

\section{Funding:}

\section{Product link:}

Source: Kansai University, Teijin Develop World's First Piezoelectric Fabrics for Wearable Devices http://www.textileworld.com/Articles/2015/January/Kansai University Teijin Develop Worlds First Pi ezoelectric Fabrics for Wearable Devices

\subsubsection{Nottingham Trent University's Advanced Textiles Research Group}

Technology name: Smart garments

Description: The Nottingham Trent University Advanced Textiles Research Group received \$3.1 million to support its R\&D in "embedding electronics, including LEDs, sensors and micro-controllers, directly into yarns which can then be used to make a wide range of goods, such as clothes, accessories, and car seats."

Status: Evolving

Funding: USD \$3.1 million from the Engineering and Physical Sciences Research Council, for a total of total of USD \$4.3 million to support the 4-year project; as well as contributions totaling USD \$660,000, from partners including Stretchline, the Defense Science and Technology Laboratory, Speedo, BSN Medical, Royal Center for Defense Medicine, International Automotive Components, Plessey Semiconductors, Urgo Ltd, the Centre for Process Innovation, and MediCity.

\section{Product link:}

Source: Nottingham Trent University receives $£ 2 \mathrm{~m}$ grant to develop wearable technology methods http://www.biometricupdate.com/201501/nottingham-trent-university-receives-2m-grant-to-developwearable-technology-methods

\subsubsection{PNI Sensor Corp: SENtrode}

Technology name: SENtrode development kit 
PNNL RTA Monthly Report - January 2015

Sensors

Description: SENtrode integrates essential hardware components for wearables and other Internet-ofThings products into one form-factor board. SENtrode is a "wristwatch-sized hardware platform [that] integrates sensors, PNI's SENtral sensor hub, sensor fusion algorithms, programmable processor, and wireless capabilities. It includes a gyroscope, accelerometer, magnetic sensor, pressure and optical heart rate sensor readings, as well as a rechargeable $70 \mu \mathrm{Amp}$ hour battery and sensor fusion algorithms for ecompass, step counting, barometric pressure, relative humidity, and more. The developers report that humidity and gas sensors will be available.

Status: Evolving - Anticipated to be ready in March

\section{Funding:}

\section{Product link:}

Source: SENtrode Wearable Development Kit http://www.pnicorp.com/products/sentrode

\subsubsection{StretchSense}

Technology name: StretchSense fabric sensor

Description: StretchSense "provides precision information in real-time for soft objects." The StretchSense kit includes flexible fabric stretch sensor, Bluetooth LE circuit, coin cell battery, and a data capture app. StretchSense is easily worn and integrated into clothing and it transmits motion information to its app. The technology is in use by "by over 80 customers in 15 countries who have incorporated its sensors in a wide range of applications in areas including healthcare, sports and motion capture."

Status: Soon to be released

Funding: According to the article, "StretchSense recently completed a capital raise, with investors including Flying Kiwi Angels and the New Zealand Venture Investment Fund. The funds will be used for business development, increasing production capacity and securing intellectual property."

Product link: http://www.stretchsense.com/

Source: StretchSense joins global elite of wearable tech firms http://www.scoop.co.nz/stories/BU1501/S00350/stretchsense-joins-global-elite-of-wearable-techfirms.htm

\subsubsection{Sunfriend}

Technology name: Sunfriend wearable UVA+B detector

Description: The waterproof device features "internationally recognized scientific-based sun safety approved algorithms and NASA inspired" UV sensor that takes a reading from the environment every few seconds. An LED light flashes when the user has had enough Vitamin D.

Status: Available

Funding: According to the article, the company is seeking funders and distributors. 
PNNL RTA Monthly Report - January 2015

Sensors

Product link: http://sunfriend.com/

Source: The SunFriend wearable protects you from sunburn http://venturebeat.com/2015/01/09/the-sunfriend-wearable-protects-you-from-sunburn/

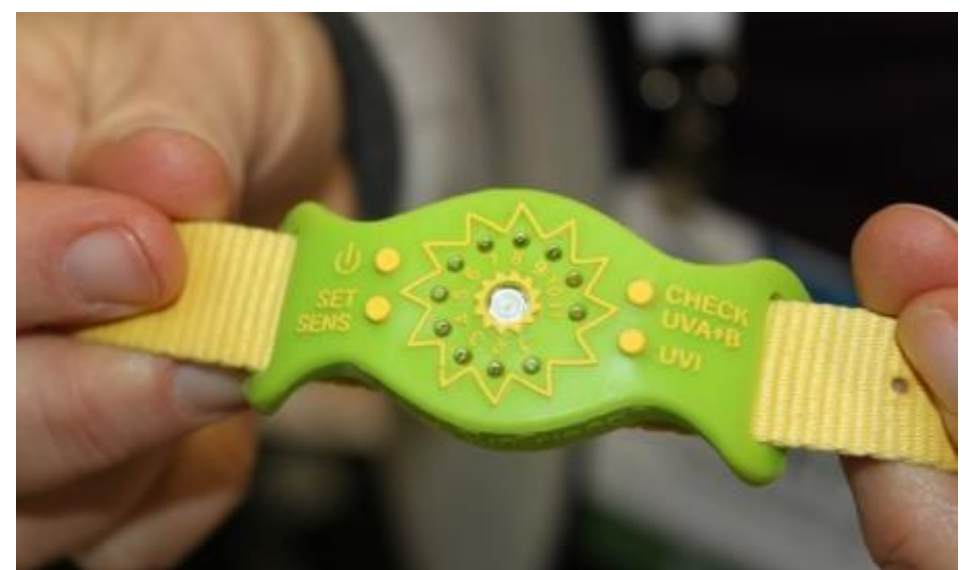

Photo Source: http://venturebeat.com/2015/01/09/the-sunfriend-wearable-protects-you-from-sunburn/ 

PNNL RTA Monthly Report - December 2014

Displays

\subsection{Displays}

\subsection{Heads-up (on face or head)}

\subsubsection{Squared, Autodesk}

Technology name: Wearables for construction industry

Description: 3Squared and Autodesk are collaborating to explore how wearables can benefit the construction industry, including improving "information delivery, enhance on-site communication between engineers, and enhance health and safety." They are piloting smartglasses with Building Information Modelling 360 Field, a construction management application. They will also be exploring how "to deliver project documentation directly to an engineer on-site, to capture video and pictures and other field data during the commissioning and handover of a building project" as well as "how to provide access to drawings and plans and how technology such as iBeacon could be used to deliver contextualbased information on site."

Status: Evolving

Funding:

Product link:

Source: Sheffield software firm partners with Californian 3D company to develop wearable technology https://bdaily.co.uk/technology/22-01-2015/sheffield-software-firm-partners-with-3d-firm-to-developwearable-technology/

\subsubsection{Avegant: Glyph}

Technology name: Glyph headset

Description: Glyph is lightweight (16 oz.) headset with a Micromirror Array virtual retina display that "projects images directly onto your retina, creating sharp, stark images." The device includes a 45-degree field of view, HDMI port, and 3-hour video/48-hour audio battery life.

Status: Evolving - expected to be ready to ship in fall 2015.

Funding: Crowdfunding - Successfully funded in 2014

Product link: http://avegant.com/

Source: Avegant's headphone-like wearable display arrives this fall http://www.engadget.com/2015/01/04/avegant-glyph-finished-design/ 
PNNL RTA Monthly Report - December 2014

Displays

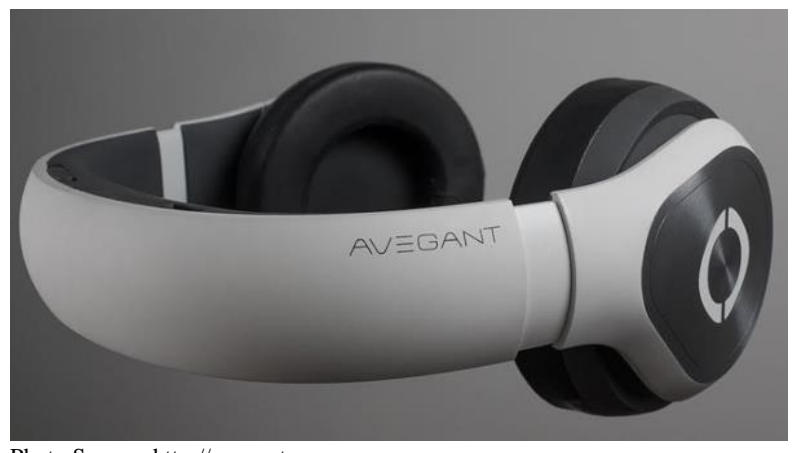

Photo Source: http://avegant.com

\subsubsection{Avegant: Jellyfish}

Technology name: Jellyfish video glasses

Description: The Jellyfish video headset provides a wide (65-degree) field of view optimal for "things like simulators, virtual reality, and point-of-view drone flying." The article describes the author's experience with the technology, noting that "the larger image in front of your eyes, and its sharpness, are a huge step up from most of the units currently on the market. I could make out individual blades of grass with the drone hundreds of feet in the air. The stony, arid surface of the desert leaped out in sharp clarity."

Status: Evolving

\section{Funding:}

Product link: http://avegant.com/

Source: We flew over the Nevada desert with Avegant's 'Jellyfish' video glasses http://www.engadget.com/2015/01/10/avegant-jellyfish-hands-on/

\subsubsection{Forcite: Alpine}

Technology name: Alpine smart helmet

Description: This smart helmet features an HD camera, GPS tracking, speakers, microphone, OLED fog lights, impact sensors, emergency beacon, and micro-computer that communicate with a smart phone app with analytics capabilities. The device is wi-fi and Bluetooth enabled. It features a 6-8 hour battery life, 160-degree field of view, and the ability to communicate with others in the area.

Status: Evolving

Funding:

Product link: http://forcite.com.au/alpine-v2/

Source: Forcite Alpine Smart Helmet for Snow Sports http://www.coolwearable.com/forcite-smart-helmet/ 


\subsubsection{Microsoft: HoloLens}

Technology name: HoloLens virtual augmented reality glasses

Description: HoloLens glasses project holographic displays onto surfaces around the user. All of the computing components are featured in the headset itself, so it does not require cables or use of a secondary device. Proposed example applications include "transformation of an ordinary wall into a huge Netflix-playing television, or using your empty desk space to spray paint a virtual rocket ship model."

Status: Soon to be released

\section{Funding:}

Product link: http://www.microsoft.com/microsoft-hololens/en-us

Source: Microsoft's vision of virtual reality wearables is a lot more exciting than everyone else's http://phandroid.com/2015/01/21/microsoft-hololens-wearable/

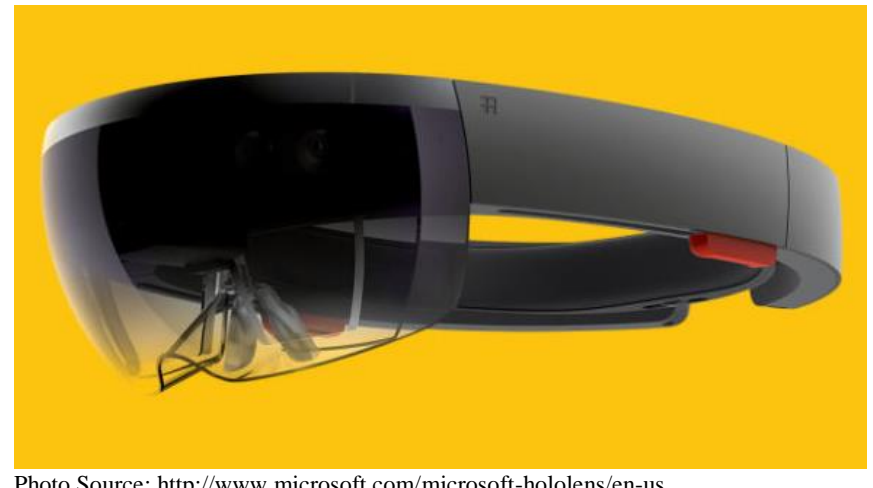

Photo Source: http://www.microsoft.com/microsoft-hololens/en-us

\subsubsection{Moggles}

Technology name: Moggles virtual reality system

Description: Moggles is a virtual reality system that "uses the display and motion sensors of your smartphone and tracks the motions of your head to give the phone display real time updates about in which direction you are looking." Sensors in the user's phone tracks his or her head movement and updates the viewport of the phone screen. It offers features hand controller with sensors to track your hand movement and an earphone jack. The device works with smartphones up to 5.5 inches.

Status: Evolving

\section{Funding:}

Product link: http://www.moggles.com/

Source: Moggles: Virtual Reality Headset for Smartphones http://www.coolwearable.com/moggles-virtual-reality/ 
PNNL RTA Monthly Report - December 2014

Displays

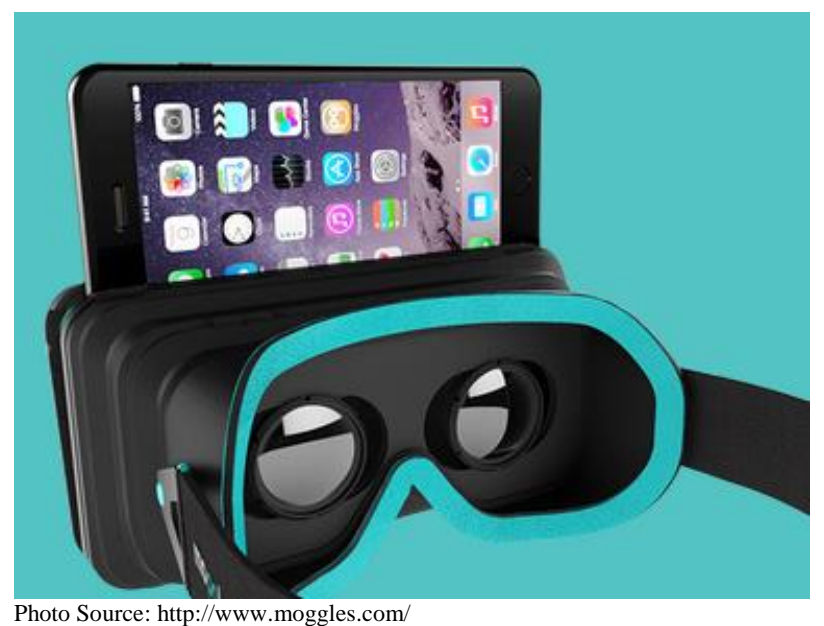

\subsubsection{Osaka University}

Technology name: Intelligent text management system

Description: This system "actively manages movement of text in a user's field of view." The device responds to the need for "a method to migrate user-centric content such as e-mail or text messages throughout a user's environment while mobile." The researchers are using camera tracking to recognize a route on which the user is traveling and move text from one viable location to the next to maximize readability. The research aims to help readability of text on see-through heads-up displays.

Status: Evolving

\section{Funding:}

\section{Product link:}

Source: Dynamic text management for see-through wearable and heads-up display systems http://dl.acm.org/citation.cfm?id=2449443\&preflayout=tabs

\subsubsection{Syndiant}

Technology name: Head-mounted display

Description: Syndiant is developing immersive optical modules for head-mounted displays that are fixed focus, light weight, and low-power consuming with integrated RGB LED illumination. The device's "combination of the SYL2271 with optimized optical components provides an excellent solution for any near-eye immersive application that requires a large virtual image with outstanding picture quality" and is optimal for head-mounted displays. The device provides " $1280 \times 720 \mathrm{HD}$ resolution in a large 80 -inch at 4.5-meters virtual screen .... excellent image quality with vivid colors and form factor designed for the wearable near-eye display market."

Status: Evolving

\section{Funding:}


PNNL RTA Monthly Report - December 2014

Displays

Product link: http://www.syndiant.com

Source: Syndiant Showcases Head-Mounted Displays at CES

http://www.prnewswire.com/news-releases/syndiant-showcases-head-mounted-displays-at-ces-

$\underline{300015241 . h t m l}$

\subsubsection{Toshiba: Toshiba Glass}

Technology name: Toshiba Glass

Description: Toshiba Glass provides a heads-up display on wherever the user is looking, rather than on a smartphone or computer. Compared to Google Glass, "the Toshiba unit projects the display directly onto the lens." Toshiba Glass is tethered to receive information and power from a secondary device. Toshiba described potential applications such as "reading a recipe whilst cooking and using a warehouse indoor map to help the wearer locate inventory."

Status: Evolving

\section{Funding:}

\section{Product link:}

Source: Toshiba Demonstrate Their Take On A Glass Wearable, Out Later This Year http://www.androidheadlines.com/2015/01/toshiba-demonstrate-take-glass-wearable-later-year.html

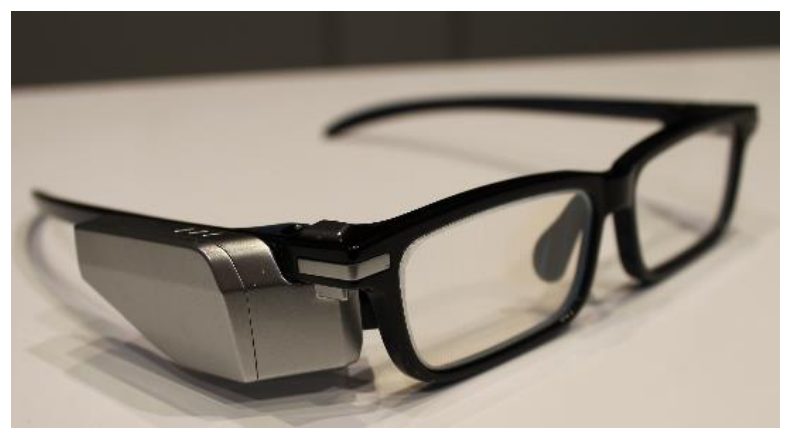

Photo Source: http://androidheadlines.com/2015/01/toshiba-demonstrate-take-glass-wearable-later-year.html

\subsubsection{Vuzix}

Technology name: Next-generation optics

Description: Vuzix, smart glasses and eyewear producer, received \$24.8 million from Intel to produce the "next generation optics and displays that have the potential to fit in fashion-based wearable glasses." The investment will be used for "general working capital to accelerate the introduction of Vuzix nextgeneration fashion-based wearable display products into the consumer market." Vuzix's portfolio includes "personal display and wearable computing devices that offer users a portable high quality viewing experience, provide solutions for mobility, wearable displays and virtual and augmented reality."

Status: Evolving 
PNNL RTA Monthly Report - December 2014 Displays

Funding: \$24.8 million investment from Intel

Product link: http://www.vuzix.com/

Source: Vuzix Corporation Receives \$24.8 Million Investment From Intel Corporation http://www.marketwatch.com/story/vuzix-corporation-receives-248-million-investment-from-intelcorporation-2015-01-02?reflink=MW_news_stmp 
PNNL RTA Monthly Report - January 2015

Power

\subsection{Power}

\subsection{Self-powering (Harvesters)}

\subsubsection{Hahn-Schickard-Gesellschaft Institute for Micromachining and Information Technology}

Technology name: Shock and swing shoe-worn harvesters

Description: The shock harvester "generates power when the heel of a shoe strikes the ground whilst the so-called swing harvester generates power when the foot is swinging." The technology is part of the 9DSense project "aimed to enhance the battery life of an indoor navigation system" that features a threeaxis accelerometer, gyroscope, and magnetic field sensor. The developers propose that "Rescue units could, for example, track their motion within a building they don't know on their handheld devices." Technical specifications include "the swing harvester is $41 \mathrm{~mm}$ x $70 \mathrm{~mm} 15 \mathrm{~mm}$, weighs approximately $25 \mathrm{~g}$ in one iteration and generates an average power output of $0.84 \mathrm{~mW}$. The shock harvester has dimensions of $40 \mathrm{~mm} \times 60 \mathrm{~mm} \times 20 \mathrm{~mm}$, weighs $150 \mathrm{~g}$ and has been able to generate a maximum of $4.13 \mathrm{~mW}$ of power when a test subject was travelling at $5 \mathrm{~km} / \mathrm{h}$ on solid ground." The devices generated enough power for temperature readings (from a temperature sensor in the shoe) to be wirelessly transmitted over $10 \mathrm{~m}$ to a handheld device.

Status: Evolving

Funding:

Product link:

Source: Taking steps to power wearable tech http://www.theengineer.co.uk/news/taking-steps-to-power-wearable-tech/1019716.article

\subsubsection{Korea Advanced Institute of Science and Technology TEGway}

Technology name: Wearable thermos-element

Description: KAIST's wearable thermo-element was selected in the top ten IT technologies at the 2015 Netexplo Award in partnership with the UNESCO. The technology can reportedly "generate electricity from human body heat and is very light and thin to easily put on clothes. It can also be applied not only to human body but also to a variety of devices generating waste heats such as many equipment in cars, planes and factories." It can be "incorporated into clothing to power phones and other mobile devices" as well as wrapped around other appendages such as an armpit or thigh for maximum heat exposure.

Status: Evolving

Funding:

Product link:

Source: KAIST's body heat-powered wearable selected as one of top ten IT technologies by UNESCO 
http://www.whowired.com/news/articleView.html?idxno=406603

\subsubsection{Korea Advanced Institute of Science and Technology: ZnO}

Technology name: $\mathrm{ZnO}$ piezoelectric micro energy harvesters "nanogenerators"

Description: $\mathrm{ZnO}$ nanogenerators, are small energy harvesters made up of "piezoelectric $\mathrm{ZnO}$ nanorod or nanowire arrays sandwiched between two electrodes formed on the flexible substrates." In this project, researchers propose piezoelectric $\mathrm{ZnO}$ /aluminum nitride stacked layers for use in nanogenerators and "found that the added layer increased the output voltage a whopping 140 to 200 times." Researchers expect the technology to "provide effective approaches for realizing highly energy-efficient ZnO-based nanogenerators and extended applications of nanogenerators, such as self-power sources and sensor devices."

Status: Evolving

Funding: Supported by Basic Science Research Program through the National Research Foundation of Korea funded by the Ministry of Education (Grant No. 2013R1A1A2005942); also partly supported by K-Valley Research, Education, Development \& Business Project funded by the Korea Advanced Institute of Science and Technology.

Research link: http://dx.doi.org/10.1063/1.4904270

Source: Energy Harvesting output voltage increased from 7 millivolts to 1 volt will enable better wearable electronics http://nextbigfuture.com/2015/01/energy-harvesting-output-voltage.html

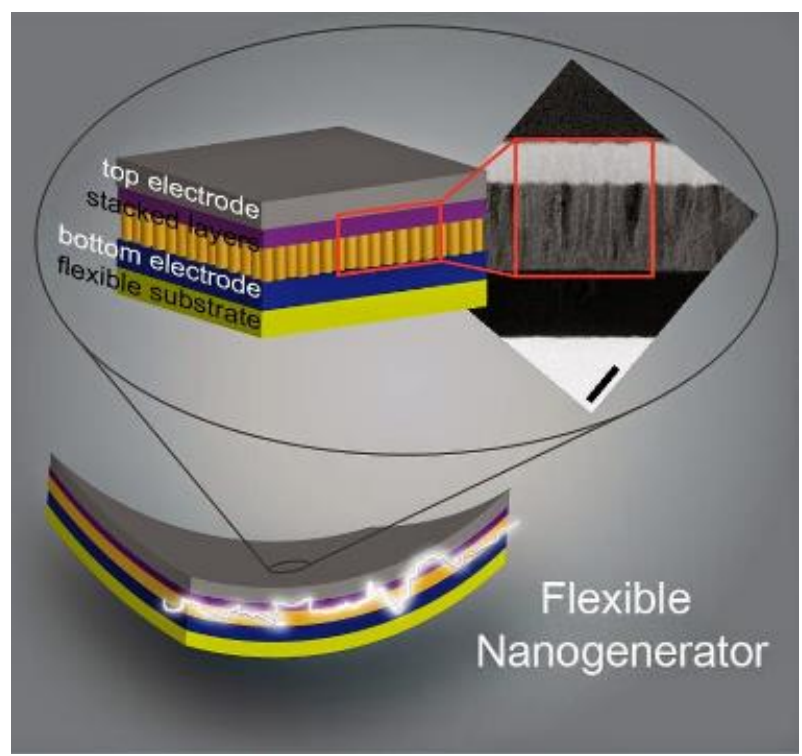

Photo Source: http://nextbigfuture.com/2015/01/energy-harvesting-output-voltage.html

\subsubsection{Korea Institute of Science and Technology, et al.}

Technology name: Flexible, self-powered piezoelectric sensor 
Description: In this research, "Highly-stretchable piezoelectric hemispheres composed composite thin film nanogenerators are fabricated as a self-powered, exceptionally sensitive sensor for providing sensitive motion information from a human body." The researchers propose that piezoelectric nanogenerators can function as motion sensors, detecting even the slightest displacements. In the device's motion sensor mode, researchers demonstrated "the potential for the use of piezoelectric nanogenerators as ultrasensitive strain sensors in smart skin applications," and they hope their device can ultimately help "monitor the instability and gait disturbances common in patients suffering from diseases such as Alzheimer's or Parkinson's."

Status: Evolving

\section{Funding:}

\section{Product link:}

Source: Wearable self-powered motion sensor http://www.materialstoday.com/energy/news/wearable-selfpowered-motion-sensor/

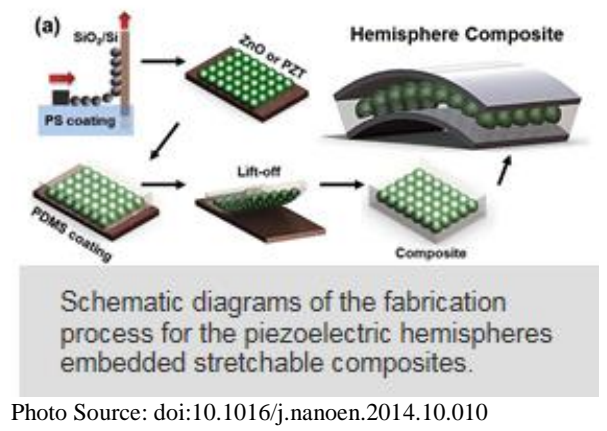

\subsubsection{National University of Singapore}

Technology name: Flexible generators

Description: These small, flexible generators that convert muscle movements or friction-inducing motion into power (turning mechanical energy into electrical energy). Researchers propose that "Such frictionpowered generators could usher new types of wearable sensors that do not require batteries but instead are powered by the wearer's daily activities like walking, talking or holding an object." The technology was demonstrated to produce " 90 volts of open circuit voltage when touched gently with a finger." Proposed applications include use in wearables to track motion and activity.

Status: Evolving

\section{Funding:}

\section{Product link:}

Source: Skin-Based Generators Scavenge Muscle Motion to Power Wearables http://spectrum.ieee.org/tech-talk/biomedical/devices/skinbased-generators-scavenge-muscle-motion-topower-wearables 


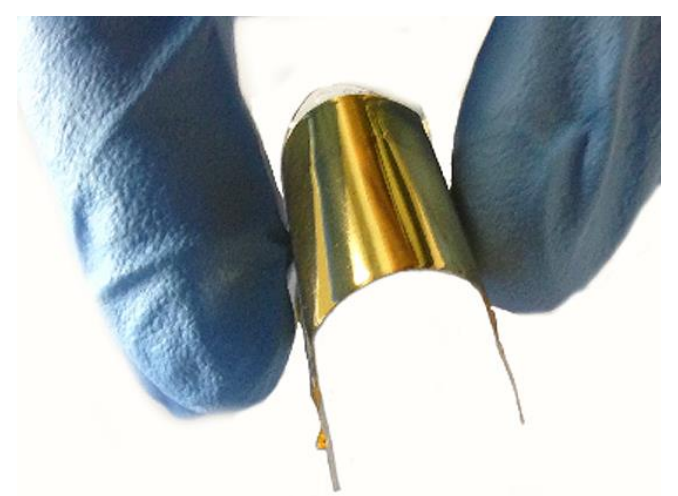

Photo Source: http://spectrum.ieee.org/tech-talk/biomedical/devices/skinbased-generators-scavenge-muscle-motion-to-power-wearables

\subsubsection{Sogang University Micro \& Nano Engineering Laboratory (MNELAB)}

Technology name: Body motion energy harvester

Description: Researchers are developing a "body motion energy harvester, with the flexibility and elasticity to be applied to high-flexion joints and suitable for integration with fabrics," with proposed applications of providing power for medical wearables. The increased flexibility and elasticity allow the kinetic energy harvesters to be placed on body parts that create the most kinetic energy. The researchers expect "in actual body-worn application, a $10 \mathrm{x} 10 \mathrm{~cm}$ square patch incorporating these structures should be capable of producing several dozen milliwatts, which is the power level of some hearing aids, pacemakers, neurological stimulators and cochlea implants. It would also be sufficient for use as an auxiliary power source for a smart phone or smart watch."

Status: Evolving

Funding: Supported by the Pioneer Research Center Program (2010-0019453) and the ITRC (Information Technology Research Center) support program (NIPA-2014-H0301-14-1008) supervised by the NIPA (National IT Industry Promotion Agency) through the Ministry of Education, Science and Technology, Korea.

Research link: $\underline{\text { http://dx.doi.org/10.1049/el.2014.3400 }}$

Source: Body motion energy harvester may power medical and consumer wearable devices http://phys.org/news/2015-01-body-motion-energy-harvester-power.html 


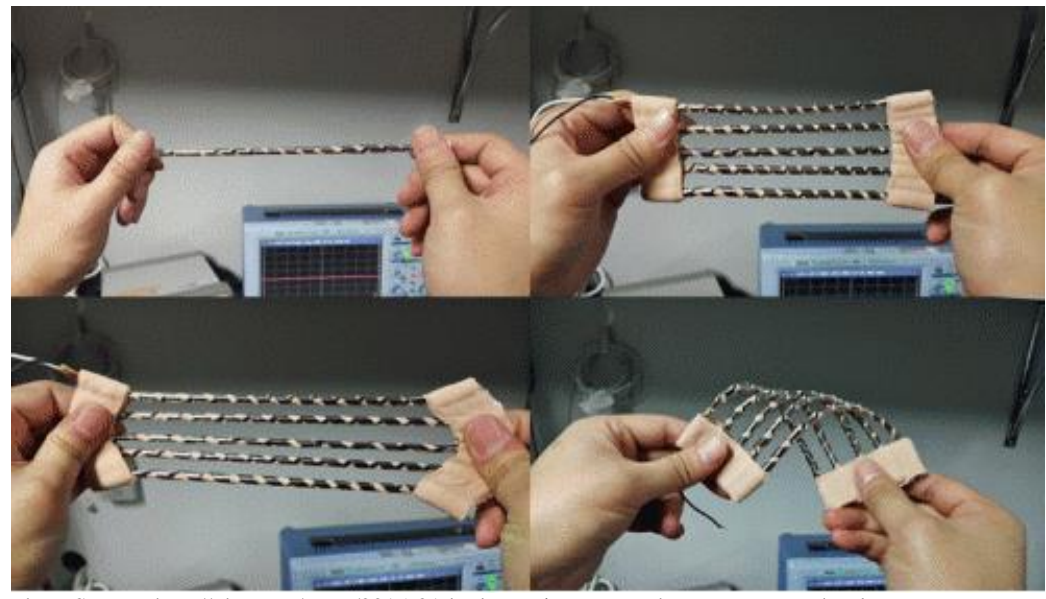

Photo Source: http://phys.org/news/2015-01-body-motion-energy-harvester-power.html

\subsection{Power supplies}

\subsubsection{Imprint Energy: ZincPoly ${ }^{\mathrm{TM}}$}

Technology name: ZincPoly ${ }^{\mathrm{TM}}$ print batteries

Description: ZincPoly is a printed battery technology that reportedly "removed longstanding limitations on the rechargeability of zinc-based batteries and enables the production of ultrathin, flexible, high energy density rechargeable batteries for significantly lower cost and without the design limitations or safety concerns of other battery technologies." The batteries are rechargeable and created with non-toxic, nonvolatile materials.

Status: Evolving

Funding: \$6 million A round led by Phoenix Venture Partners.

Product link: http://www.imprintenergy.com/

Source: Imprint Energy: Revolutionizing Wearables with Printed Batteries http://www.techfaster.com/imprint-energy-revolutionizing-wearables-with-printed-batteries/

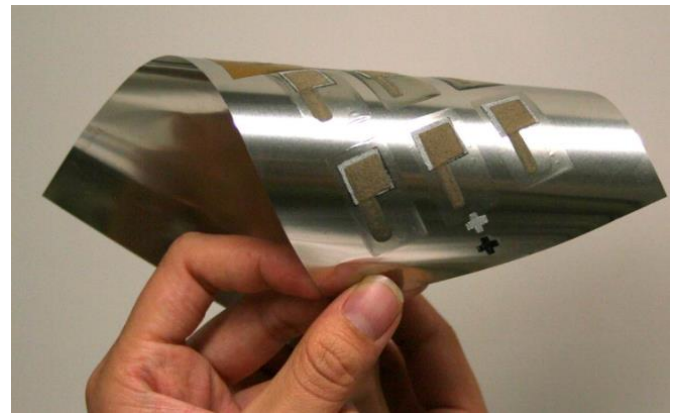

Photo Source: http://techfaster.com/imprint-energy-revolutionizing-wearables-with-printed-batteries/ 


\subsubsection{Jenax}

Technology name: Foldable battery

Description: Jenax is developing a foldable battery with increased capacity compared to standard batteries. The battery can "tolerate 1,000,000 times bending in its complete life cycle," withstand extreme temperatures, and its thickness can range from $35-20 \mathrm{~cm}$ depending the end product. Safety tests demonstrated folding of more than 200,000 times without any negative performance effects.

Status: Evolving

\section{Funding:}

Product link: http://jenaxinc.com/

Source: South Korea's Wearable Foldable Battery: Watt Was That?

http://inventorspot.com/articles/south-koreas-wearable-foldable-battery-watt-was\#sthash.RuHjBSf4.dpuf

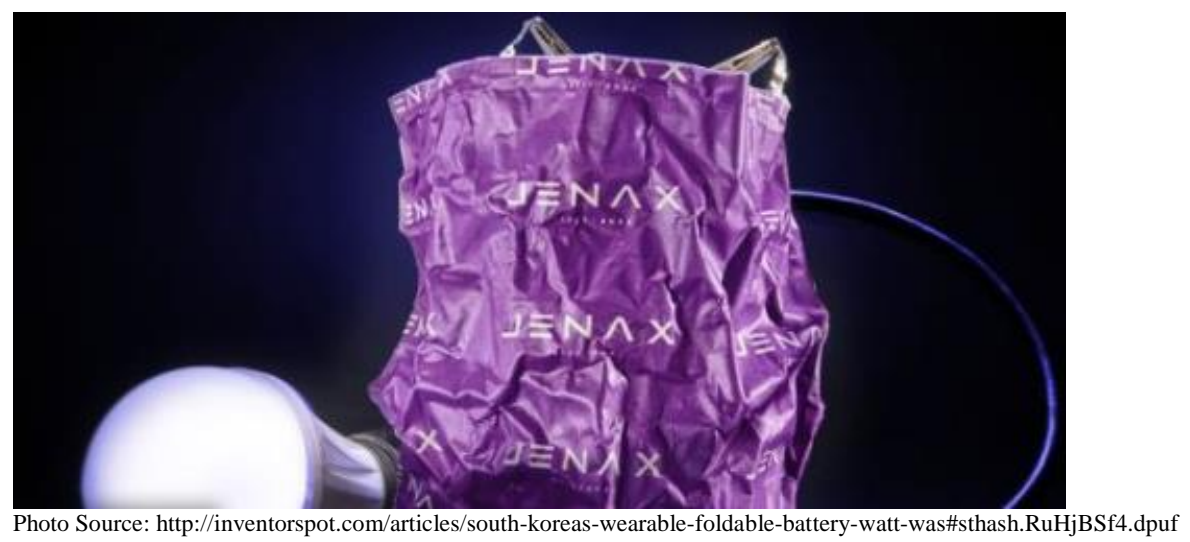

\subsubsection{Rice University}

Technology name: Supercapacitors

Description: Researchers used laser-induced graphene to produce supercapacitors, energy-storage devices for use in wearables, building on UCLA California NanoSystems Institute demonstration of using porous graphene as supercapacitor electrodes. Researchers "charged and discharged the devices for thousands of cycles with almost no loss of capacitance. In addition, the vertically-stacked supercapacitors showed almost no change in electrical performance when flexed, even after 8,000 bending cycles."

Status: Evolving

Funding: Supported by funding from the Air Force Office of Scientific Research and Multidisciplinary Research Program of the University Research Initiative

Research link: http://pubs.acs.org/doi/abs/10.1021/am509065d

Source: Laser-Made Graphene Makes Flexible Supercapacitors for Wearables 
PNNL RTA Monthly Report - January 2015

Power

http://spectrum.ieee.org/nanoclast/semiconductors/nanotechnology/graphenebased-supercapacitorsenable-wearable-electronics

\subsubsection{Toes Opto-Mechatronics}

Technology name: Thin-film lithium battery

Description: Toes Opto-Mechatronics is developing thin-film batteries delivering "the safety, ultrathinness, flexibility, and high capacity" fit for smart cards and wearable technologies. Compared to previous development methods, allegedly with Toes capability "mass production at accelerated speed is made feasible." Toes "uses manganese dioxide (positive electrode) and lithium metal (negative electrode) to form colloidal electrolyte with high polymer so that the battery resembles a liquid battery but better adapts to extreme high or low temperature environments without safety concern such as leakage."

Status: Evolving

Funding:

Product link: http://www.toes.com.tw/

Source: Toes Opto-Mechatronics launches flexible thin-film battery, seizing smart wearable application opportunities

http://www.digitimes.com/supply_chain_window/story.asp?datepublish=2015/01/12\&pages=PR\&seq=20 $\underline{2}$

\subsubsection{University of Central Florida}

Technology name: Energy-storing and energy-conducting super capacitor wire

Description: The Nano Energy-Photonics Group at the University of Central Florida has produced "a single wire that both conducts and stores electricity." While developing flat supercapacitors, developers recognized the opportunity to essentially "wrap the super capacitor around the wire and store the energy at the same time as transmitting it." Developers suggest that "Using super capacitor wires to provide stored energy, lithium-ion battery life could be vastly increased from an average of 1,000 charge/discharge cycles to nearly one million" and propose numerous applications such as "cell phones and devices like tablets could readily adapt the new technology to extend battery life" and "vehicles including aircraft and hybrid-electric cars could benefit by using the wires to reduce weight and increase storage capacity."

Status: Evolving

\section{Funding:}

Product link:

Source: High-tech with a flexible, wearable twist http://www.wpmobserver.com/news/2015/jan/08/high-tech-flexible-wearable-twist/ 

PNNL RTA Monthly Report - January 2015

Communications

\subsection{Communications}

\subsection{Hands-free Operations}

\subsubsection{Fujitsu Laboratories Ltd}

Technology name: Near-field communications ring

Description: Fujitsu developed "a compact and lightweight wearable ring-type device that offers handwriting-input functionality and a reader for near-field communications tags" as well as hands-free operations. The air-writing feature demonstrated $95 \%$ recognition accuracy and distinguishes "between the finger strokes that make up the letterform and the empty spaces that the finger moves through between the strokes." The ring "identifies the fingertip movements users make as they write in the air, and recognizes that tracing as a letterform. By writing in the air with one's fingertip, operators can select menu options or make memos on photos that they take in the field." The device features "motion sensors for text input, an NFC tag reader, and wireless communication functionality" and allow s a user to "can be used to enter numbers and take notes using handwriting in the air. In addition, an NFC tag reader enables the operator to tap on a tagged object to display the appropriate information on a relevant operation's details or instructions."

Status: Evolving

\section{Funding:}

\section{Product link:}

Source: Fujitsu Laboratories Develops Ring-Type Wearable Device Capable of Text Input by Fingertip http://www.fujitsu.com/global/about/resources/news/press-releases/2015/0113-01.html

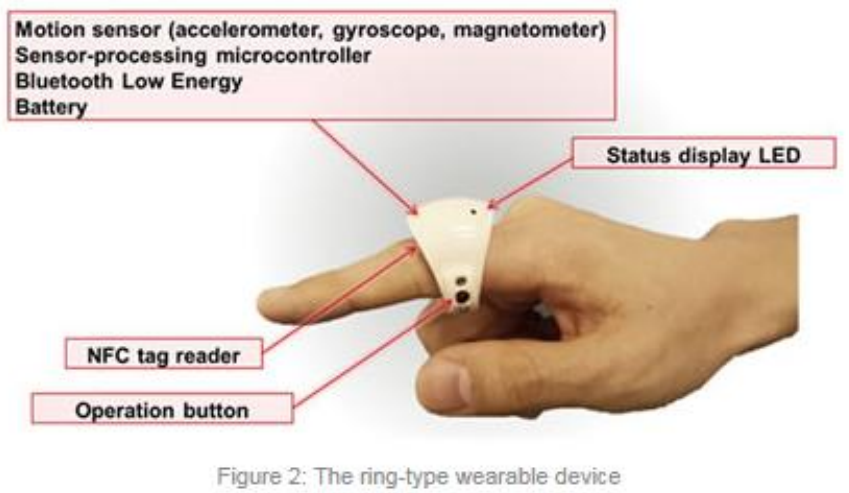

Photo Source: http://www.fujitsu.com/global/about/resources/news/press-releases/2015/0113-01.html

\subsubsection{Logbar: Ring}

Technology name: Ring 
Description: Ring allows the user to control smart devices (within a 2-meter radius) via Bluetooth using gestures. The device is available in three sizes, features a single button to operate, and comes with a charging base.

Status: Available

Funding: Crowdfunding

Product link: http://logbar.jp/ring/en/

Source: Ring wearable gesture device hands-on http://www.slashgear.com/ring-wearable-gesture-device-hands-on-04361932/

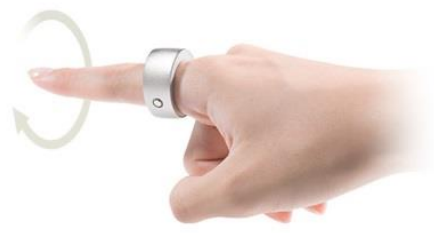

Photo Source: http://logbar.jp/ring/en/

\subsubsection{Thalmic Labs: Myo}

Technology name: Myo armband

Description: Myo is a "muscle-sensing gesture control armband" that "consists of eight muscle-sensing modules that you strap onto the widest part of your forearm, which then lets the device detect your hand gestures. These include squeezing your fist, spreading your hand, waving your hand left or right, rotating your fist, or something as minute as a quick pinch with your thumb and another finger." The device also features a gyroscope, accelerometer, and magnetometer to detect arm motion. It holds a 10-14 hour charge. The device communicates via Bluetooth-LE to the Myo Connect app to control your devices.

Status: Available - Now available on Amazon

\section{Funding:}

Product link: https://www.thalmic.com/en/myo/

Source: Muscle-sensing Myo gesture armband will be on Amazon this quarter http://www.engadget.com/2015/01/19/myo-armband-amazon/ 
PNNL RTA Monthly Report - January 2015

Communications

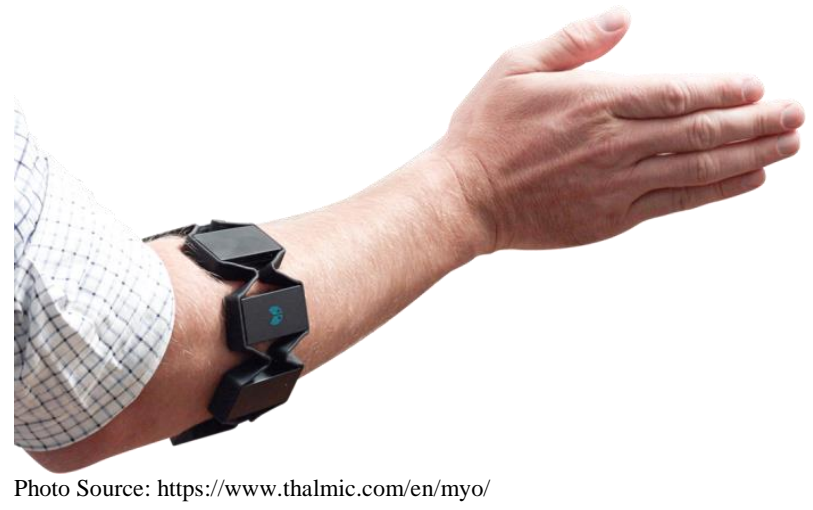

\subsubsection{Thanko}

Technology name: Wearable mouse

Description: Thanko produced a wearable mouse that "is a glove-like device that has an integrated sensor sitting atop your hand connected through a wire to two buttons, which would fit onto your index finger" and that allows you to control a smart device by maneuvering your hand like that of using a mouse, but without an actual mouse, wires, or mouse pad. The gloves feature 10-15m radius and 12-hour battery life. The sensor is the core of the device accompanied by two buttons acting as the left- and rightclick buttons.

Status: Available

Funding:

\section{Product link:}

Source: Is the Wearable Mouse from Thanko Worth the Money? http://www.niftyreads.com/wearable-mouse-thanko-worth-money/

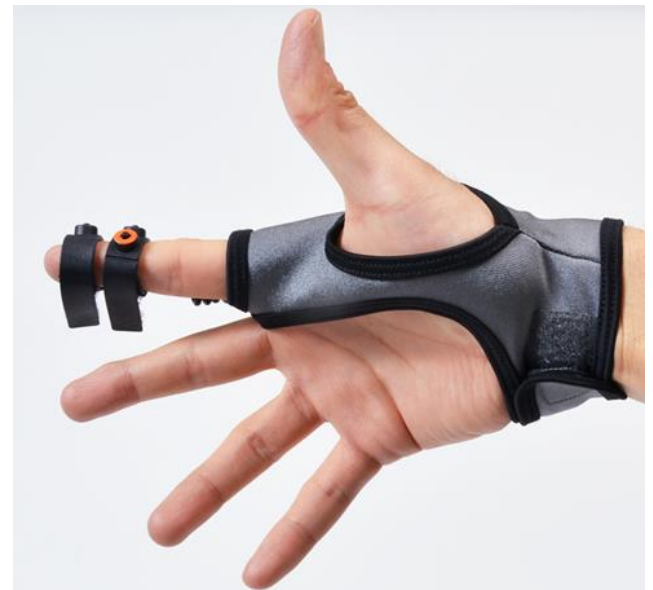

Photo Source: http://www.niftyreads.com/wearable-mouse-thanko-worth-money/ 
PNNL RTA Monthly Report - January 2015

Communications

\subsection{Short-range low-power Bluetooth}

\subsubsection{Cynaps: Mint}

Technology name: Mint, a 3D-printed, customizable bone conduction headset

Description: The bone conduction headset produces "super clear audio through vibration, via Bluetooth from your phone, tablet, PC and many smartwatches" without blocking the user's ears. The device uses Bluetooth to connect to smart devices and wirelessly allows users to receive notifications from their smart devices. It is comprises a series of modules that are modifiable to attach to helmets, hats, goggles, and other articles of clothing.

Status: Available

Funding: Crowdfunding

Product link: http://www.maxvirtual.com/

Source: Cynaps Mint: Integratable Bone Conduction Headset https://www.indiegogo.com/projects/cynaps-mint-integratable-bone-conduction-headset

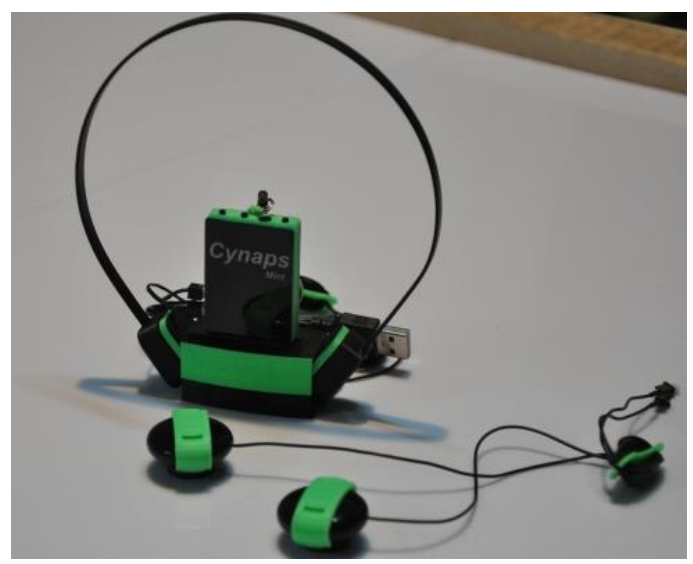

Photo Source: http://www.maxvirtual.com/

\subsubsection{TOG}

Technology name: TOG Bluetooth-enabled open-source button

Description: TOG is a modular "ultra- small Bluetooth-enabled open-source button that is slightly larger than a microSD card" that can remotely control Bluetooth-enabled devices. According to the developer's website, "When you press Tog it will wake up and communicate with your phone to execute pre-assigned actions. TOG ships with the ability to activate Siri/Google or take a picture on your smart phone with no apps required. Additionally, you may configure it to control or mute your music." As a modular device, Tog can operate standalone, but TOGMods are also available to magnetically attach to extend the functionality of Tog. The touch sensor and user-replaceable battery than can last for "months." Users program the device via a USB dock.

Status: Evolving 
PNNL RTA Monthly Report - January 2015

Communications

Funding: Crowdfunding

Product link: http://www.gettog.com/

Source: TOG Bluetooth Enabled Arduino Wearable Open Source Button https://www.geeky-gadgets.com/tog-bluetooth-enabled-arduino-wearable-open-source-button-08-01$\underline{2015 /}$

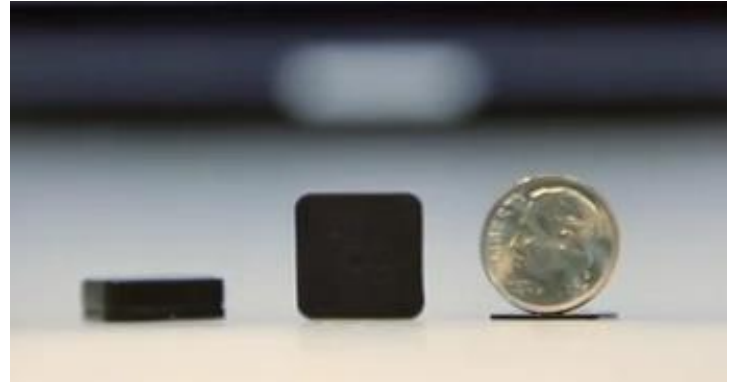

Photo Source: http://gettog.com/ 

PNNL RTA Monthly Report - January 2015

Cameras

\subsection{Cameras}

\subsubsection{Ambarella, Inc.}

Technology name: A12W Wearable Security Reference Design Kit

Description: Ambarella's A12W Wearable Security Reference Design Kit"enables fast development of a new generation of compact, ultra low-power, body-worn HD video cameras suitable for police and security applications." The Reference Design Kit features "A12W ultra low-power HD camera SystemOn-Chip [that] can encode a Full HD 1080p30 video stream plus a second HD stream for dual lens camera designs with wireless streaming." Additionally, its low power process technology delivers a long battery life fit for "wearable police and security cameras." In addition to wifi and Bluetooth capabilities, the camera "is capable of encoding Full HD at 60 frames per second (fps) or 2560x1440 at 15fps, while a second, head or shoulder mounted camera, captures video in Full HD at 30fps" and the device utilizes "a powerful ARM® Cortex ${ }^{\circledR}$-A9 CPU to run customer applications and analytics software, and also integrates on-chip de-warping for wide-angle camera designs."

Status: Available

\section{Funding:}

Product link: http://www.ambarella.com/news/68/122/Ambarella-A12W-Reference-Design-Kit-EnablesNew-Generation-of-Wearable-Police-and-Security-Cameras

Source: Ambarella A12W Reference Design Kit Enables New Generation of Wearable Police and Security Cameras http://www.marketwatch.com/story/ambarella-a12w-reference-design-kit-enablesnew-generation-ofwearable-police-and-security-cameras-2015-01-06

\subsubsection{Apple}

Technology name: Wearable action camera system

Description: Apple was granted a patent for a wearable action camera system that, similar to GoPro, can be mounted on bike helmets, scuba masks, etc. The patent describes the device as "A digital camera system [that] includes an image capture module and a remote control module. The image capture module includes an image capture system and a first wireless communication system. The remote control module includes a status display with one or more status display elements for displaying status information pertaining to the image capture module, a battery-operated power supply, one or more user controls, a second wireless communication, and a power management system providing a normal-power state and a low-power state. The system is configured such that when a user activates one of the user controls while the remote control module is in the low-power state the remote control module is set to operate in the normal-power state, a status inquiry is sent to the image capture module, and returned status information is displayed on the status display."

Status: Evolving

\section{Funding:}


PNNL RTA Monthly Report - January 2015

Cameras

Product link: http://patft.uspto.gov/netacgi/nph-

Parser?Sect1=PTO2\&Sect2=HITOFF \&p=1\&u=\%2Fnetahtml\%2FPTO\%2Fsearch-

bool.html\&r=1\&f=G\&l=50\&co1=AND\&d=PTXT\&s1=8934045\&OS=8934045\&RS=8934045

Source: Apple granted patent for GoPro-like wearable cameras

http://www.reuters.com/article/2015/01/13/us-apple-patent-idUSKBN0KM20E20150113

\subsubsection{Hammacher}

Technology name: Video-recording wifi sunglasses

Description: These sunglasses offer video capability (63-degree angle, 1080p x 1920 high-definition video at 30 frames per second), photo capability, the ability to record video and transfer it to a smartphone, and a battery life of 60 minutes - as well as UV protection of traditional sunglasses.

Status: Available

Funding:

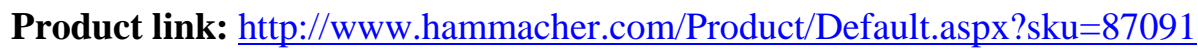

Source: Video Recording WiFi Sunglasses

http://www.coolwearable.com/video-recording-wi-fi-sunglasses/
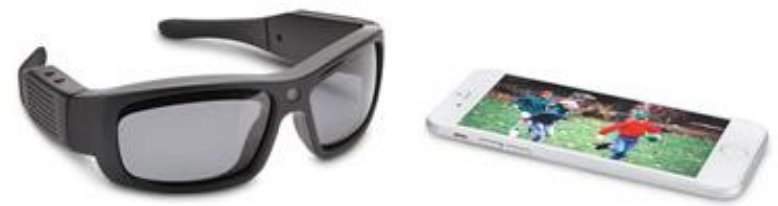

Photo Source: http://www.hammacher.com/Product/Default.aspx?sku=87091

\subsubsection{HTC: RE}

Technology name: RE wearable camera

Description: According to the HTC web site, "Designed to fit your hand seamlessly and the moment naturally, RE provides distraction-free video and photo capture. Its one-button operation won't leave you fumbling between modes, and its 146-degree wide-angle lens captures everything without a clumsy viewfinder." The device is also waterproof and there are several smart phone and Nexus accessories available include a bar mount, clip-on, and suction mount.

Status: Available

\section{Funding:}

Product link: http://www.htc.com/us/re/re-camera/

Source: HTC Introduces Wearable Camera 
PNNL RTA Monthly Report - January 2015

Cameras

http://www.malaysiandigest.com/technology/540149-htc-introduces-wearable-camera.html

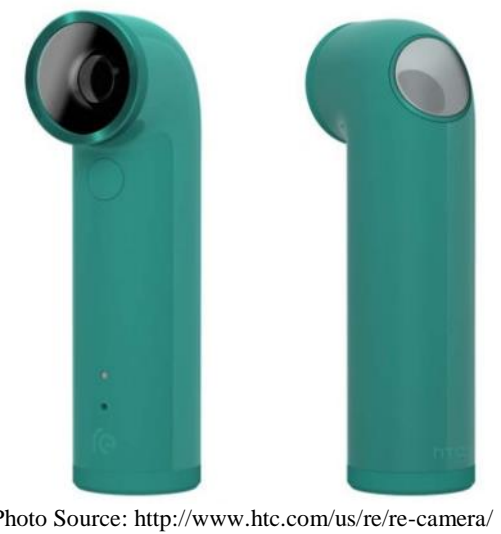

\subsubsection{Geco}

Technology name: Geco camera

Description: Geco is an easy-to-use camera with a single tactile button to operate. Geco "provides the perfect combination of fisheye and traditional angles. The lens boasts a 100 degree viewing angle for a panoramic effect on close-up shots and wider spanning shots at a distance." The compact device weighs only 20 grams, mounts easily, and has an approximately 45 minutes to 1 hour battery life.

Status: Evolving

Funding:

Product link: http://gecocam.com/

Source: Geco Cam for Your Glasses

http://gecocam.com/the-product/

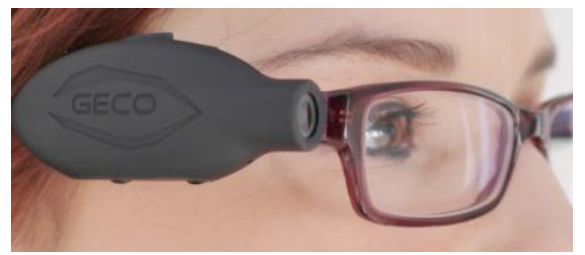

Photo Source: http://gecocam.com/the-product/

\subsubsection{GoPro: Hero 3 Black Edition}

Technology name: Hero 3 Black Edition

Description: The Go Pro Hero 3 Black Edition features "a new f. stop 2.8 and an improved speed on the wifi chip, making remote control and streaming more seamless than ever" as well as " $30 \%$ increase in battery capacity and new SuperView ultra wide screen feature."

Status: Available 
PNNL RTA Monthly Report - January 2015

Cameras

\section{Funding:}

Product link: http://shop.gopro.com/cameras

Source: Wearable Cameras Publishes New Go Pro Hero 3 Black Edition Consumer Review http://www.abc12.com/story/27764168/wearable-cameras-publishes-new-go-pro-hero-3-black-editionconsumer-review

\subsubsection{GoPro, Vislink}

Technology name: Live broadcast system for GoPro cameras

Description: GoPro and Vislink have partnered to produce a "live broadcast system for its wearable cameras." The companies will soon showcase the HD transmitter system for the Hero4 cameras. This will be the "first time official GoPro products will be available to transmit action for use during live broadcasts."

Status: Evolving

\section{Funding:}

Product link: http://gopro.com/news/gopro-partners-with-vislink-for-live-wireless-hd-broadcast

Source: GoPro teams up with Vislink for wireless wearable cameras http://www.broadcastnow.co.uk/techfacils/gopro-teams-up-with-vislink-for-wireless-wearablecameras/5081920.article

\subsection{8 iON: SnapCam}

Technology name: SnapCam

Description: SnapCam is a 1.5-inch clip-on "lifelogging" camera. The device features 8-megapixel camera, HD video capabilities, wifi/Bluetooth streaming capabilities, and a battery life of 1 week in standby, 2 hours of HD video shooting, or 5,000 photos per charge. The easy-to-use device is operated by tapping once for photo and twice for video. In addition to being wifi ready to upload photos and videos, users can shoot up to one hour of live broadcasting and streaming video.

Status: Soon to be released

\section{Funding:}

Product link: http://usa.ioncamera.com/snapcam/

Source: SnapCam is iON's new $\$ 150$ wearable lifelogging camera http://www.engadget.com/2015/01/04/snapcam-ion-life-logging-camera/ 
PNNL RTA Monthly Report - January 2015

Cameras

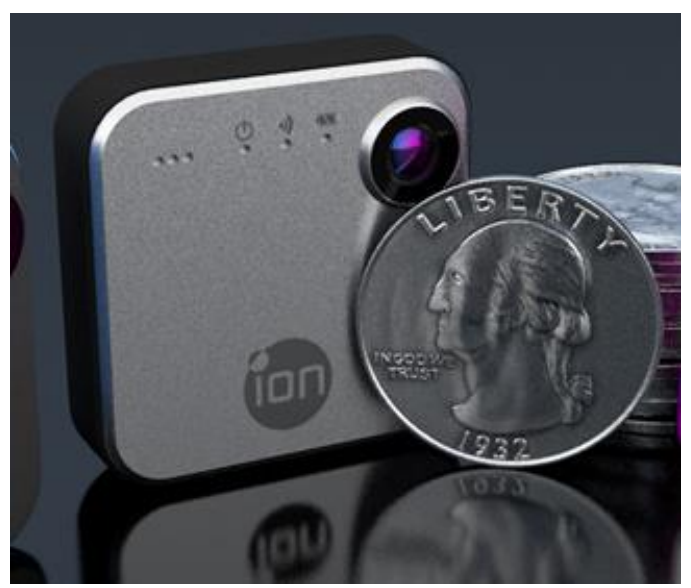

Photo Source: http://usa.ioncamera.com/snapcam/

\subsubsection{Lifelogger Technologies Corp}

Technology name: Lifelogger

Description: Lifelogger is "a fully hands-free, 5-megapixel wearable video camera that incorporates video, voice, text, and facial recognition into the camera, to fully immerse the user and others into a [point of view] experience." The device also links to the Lifelogger cloud platform, which Lifelogger is upgrading "for storing, managing and displaying videos. Starting with their 3D video timeline and adding video stabilization, geo tagging, custom in video tags, face detection, OCR, voice detection, live streaming and social sharing."

Status: Evolving

Funding:

Product link: http://lifelogger.com/

Source: Latest Updates on Lifelogger Technologies Corp (OTCMKTS:LOGG)

http://www.microcapdaily.com/latest-updates-on-lifelogger-technologies-corp-otcmktslogg/18401/

\subsubsection{Liquid Image: Ego LS}

Technology name: Ego LS wearable 4G camera

Description: The 4G Ego LS wearable camera is "enabled to integrate streaming metadata from other peripheral connected devices such as biometrics, geolocation, and other sensor information," and proposed to be beneficial for "for surveillance, babycam, and general streaming." The device features 135-degree camera angle and 4G LTE, Wi-Fi, Bluetooth, and low frequency radiofrequency, with the option to use public or private networks. The live transmission capability is proposed to have applications from "public safety and security to promotional and social uses."

Status: Soon to be released

Funding: 
PNNL RTA Monthly Report - January 2015

Cameras

Product link: http://www.liquidimageco.com/collections/ego

Source: GoPro : Wearable streaming Ego LS 4G camera from Liquid Image on display at CES 2015 http://www.4-traders.com/GOPRO-INC-16783944/news/GoPro--Wearable-streaming-Ego-LS-4Gcamera-from-Liquid-Image-on-display-at-CES-2015-19679659/

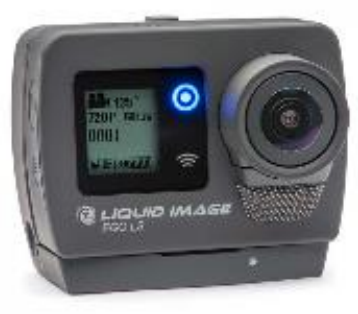

Ego LS 4 G Streaming Camera

Photo Source: http://www.liquidimageco.com/collections/ego

\subsubsection{1 m-View, Fire Cam}

Technology name: Fire Cam with streaming capability

Description: m-View has partnered with Fire Cam to combine Fire Cam's "ruggedised and heat-resistant cameras" with m-View's video streaming system comprised of "a Wi-Fi pro camera, which attaches to any shirt, vest or coat and can record high definition 1080p. It also features a 150-degree wide angle lens, LED light, and infrared light. In addition, the live streaming capability can be hosted and stored in a secure cloud or private managed system." The stream can also allow the user to stream live video, audio, and GPS data. The device is "targeted at emergency service providers and other market segments such as industrial, construction, transport, health, local council and law enforcement agencies."

Status: Available

\section{Funding:}

Product link: http://www.mview.com.au/m-view-fire-cam-pro/

Source: $\mathrm{m}$-View brings wearable Fire Cam cameras to the market http://www.arnnet.com.au/article/563767/m-view-brings-wearable-fire-cam-cameras-market/

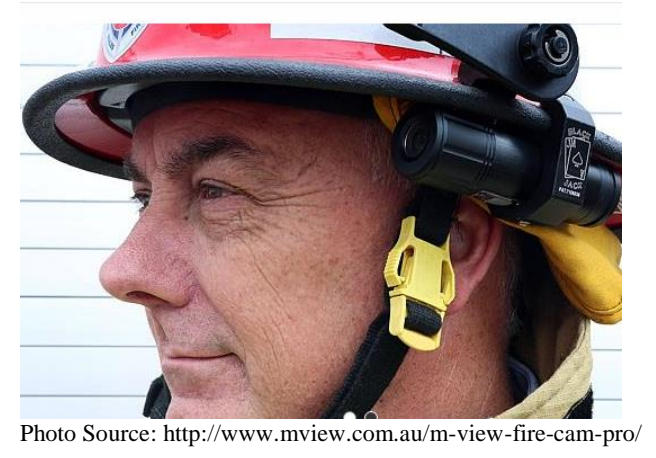




\subsubsection{Narrative Clip 2}

Technology name: Narrative Clip 2 lifelogging camera

Description: Improving on the original Narrative lifelogging camera, Narrative Clip 2 features a "flexible mount that can accommodate lapel pins and even tripods." It offers 8-megapixel, 90-degree angle unit with wifi and Bluetooth capability to sync images to your phone or other online systems. The developer cites an increased but undefined battery life.

Status: Soon to be released - anticipated 2015

\section{Funding:}

Product link: http://getnarrative.com/

Source: Say hello to the second generation of Narrative's wearable camera http://www.engadget.com/2015/01/04/narrative-clip-2/

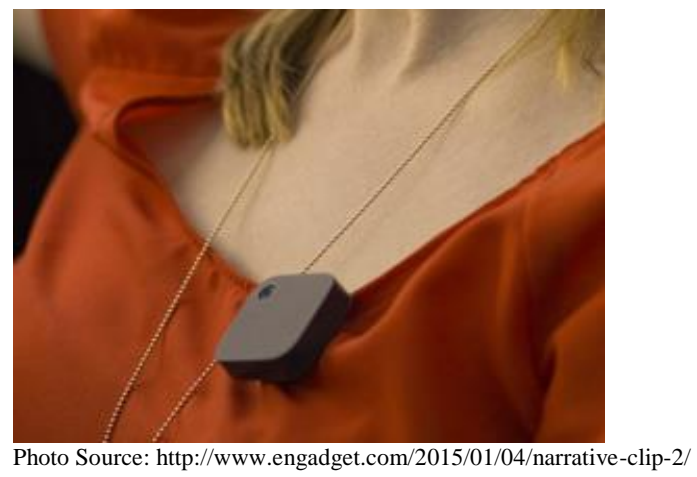

\subsubsection{Panasonic: A500}

Technology name: A500 4K mountable sports camera, virtual reality mirror

Description: The A500 wearable point-of-view sports camera is part of Panasonic's Adventure rage. The durable, wearable device is water- and dust-proof. It shoots at $4 \mathrm{k}$ video resolution at $30 \mathrm{p}$ and features an image stabilizer and built-in LCD to allow the user to see what they are shooting. The device also features NFC to connect with a smart device as well as wifi to allow for remote control.

Status: The A500 camera is available.

\section{Funding:}

Product link: http://shop.panasonic.com/cameras-and-camcorders/camcorders/HX-A500H.html

Source: CES 2015: Panasonic challenges GoPro with new wearable camera tech http://www.computerweekly.com/blogs/inspect-a-gadget/2015/01/ces-2015-panasonic-challenges-goprowith-new-wearable-camera-tech.html 


\subsubsection{TASER, EVIDENCE.com}

Technology name: AXON body-worn video camera and EVIDENCE.com cloud-based digital evidence management system

Description: Several police departments have placed orders for AXON flex cameras and services from EVIDENCE.com. Together, the device and support services allow users to easily and securely capture and store footage. The body-worn AXON cameras easily attach to glasses, hats, collars, etc., and feature wide-angle, full-color view and a pocket-size battery pack. The video is uploaded via a docking station to cloud-based EVIDENCE.com. According to the article, "EVIDENCE.com helps police capture, manage, and share their digital evidence without the complexity or cost of installing in-house servers. It enables greater transparency through seamless integration with the industry-leading AXON body-worn video cameras. EVIDENCE.com is the most secure, scalable, and cost-effective solution for managing all types of digital evidence. EVIDENCE.com automates the upload process to ensure security and integrity while keeping officers in the field rather than sitting at computers."

Status: Available

\section{Funding:}

Product link: http://www.taser.com/products/on-officer-video, https://www.evidence.com/

Source: Sonoma County Sheriff's Office Deploys AXON Wearable Cameras with EVIDENCE.com http://www.prnewswire.com/news-releases/sonoma-county-sheriffs-office-deploys-axon-wearablecameras-with-evidencecom-300020393.html

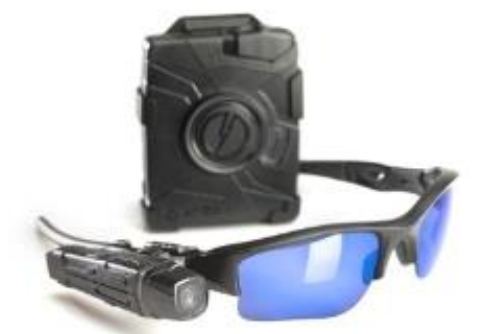

Photo Source: http://www.taser.com/products/on-officer-video 
PNNL RTA Monthly Report - January 2015

Breathing Apparatus

\subsection{Breathing Apparatus}

\subsubsection{MSA Safety Inc.: G1}

Technology name: G1: self-contained breathing apparatus (SCBA)

Description: Ottawa Fire Services is purchasing self-contained breathing apparatus by MSA Safety Inc., featuring "a 50-foot bail-out cable, among other modern features and electronic communications technology." The technology is reported to improve vision and mobility of the older units: "The air cylinders are lighter and contain 15 minutes more air. Electronics were incorporated into air regulators and communication equipment, including heads-up displays on the mask for better communications between firefighters and telemetry systems that allow monitoring and control by commanders." The G1 was certified by the National Institute for Occupational Safety and Health in the December.

Status: Available

Funding:

Product link: http://msafire.com/breathe/

Source: MSA Safety products in demand to protect workers in dangerous jobs http://triblive.com/business/headlines/7432236-74/safety-msa-sales\#axzz3QcuXEKEh

\subsubsection{Scott Safety}

\section{Technology name: Air-Pak X3 SCBA}

Description: Frederick County fire service purchased 620 new SCBAs for its firefighters. The devices feature "a slimmer, more comfortable design as well as air cylinders with 45 minutes of capacity, a marked improvement over the rescue service's bulkier current model, which carried only about 30 minutes' worth of air." They weigh 10\% less than their predecessor, and the AV-3000 HT face features a visor tested to withstand up to 500 degrees. The developer website describes the technology as including "new shoulder strap designs, better weight management, and improved hose and wire management ... Fire ground communications are enhanced with the introduction of the AV-3000 HT facepiece, EPIC 3 Communications, a new 'external' [heads-up display] and optimally positioned 'buddy' lights."

Status: Available

\section{Funding:}

Product link: https://www.scottsafety.com/en/us/Pages/ProductDetail.aspx ?productdetail=Air$\underline{\text { Pak }+ \text { X3 }+ \text { SCBA+(NFPA+2013+Approved.+Now+Shipping!) }}$

Source: Firefighters in Frederick County receive 620 new breathing apparatus units http://www.fredericknewspost.com/news/disasters and accidents/fires/new-breathing-apparatus-putsfirefighters-on-cutting-edge/article_63279c64-c307-50c9-abe1-99dac2fe5bc1.html 

PNNL RTA Monthly Report - January 2015

Exoskeletons

\subsection{Exoskeletons}

\subsubsection{Ritsumeikan University}

Technology name: Passive elements

Description: This research explores a "new type of passive element" that is "lighter, smaller, and softer than the previous passive elements" with potential applications to create wearable robots. According to the research, "the principles of the variable mechanical impedance are explained and the basic experimental results demonstrate the performance of the proposed element. Moreover, a wearable robot for virtual reality is developed by using the proposed element and it is shown that the developed wearable robot is utilized as a force display in the virtual world."

Status: Evolving

Funding:

Product link:

Source: Development of Passive Elements with Variable Mechanical Impedance for Wearable Robots http://dx.doi.org/10.1109/ROBOT.2002.1013369 

PNNL RTA Monthly Report - January 2015

Wearable Computers

\subsection{Wearable Computers}

\subsubsection{Arduboy: Ö Bluetooth Ring}

Technology name: Ö Bluetooth Ring

Description: The Arduboy O ring features a 3D-printed body and "a 64×32 monochrome OLED display, as well as a fully functional touch button. Powered by a NRF51822 chip set, the Ö Ring has the ability to receive and reply to notifications sent via Bluetooth from a smartphone, as well as display various animations such as scrolling graphics, digital and analog clocks, and more." The device has an approximately 4-hour battery life when turned on, up to 24 hours on standby mode. It utilizes an ARMM0 microprocessor. Arduboy is also the developer of Tindie, a business-card-sized computer with "a 1.3" OLED display, 32 KByte Flash Memory.”

Status: Evolving

\section{Funding:}

Product link: http://www.arduboy.com/o-bluetooth-ring/

Source: The 3D Printed Ö Bluetooth Ring is One of the Tiniest Personal Computers You Will Ever See http://3dprint.com/34627/o-bluetooth-ring-3d-printed/

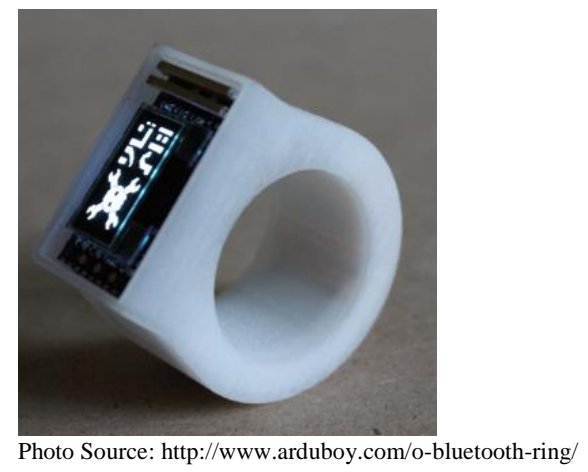

\subsubsection{Human Interactive Reliable Integrated Smartwatch (HIRIS)}

Technology name: Human Interactive Reliable Integrated Smartwatch (HIRIS)

Description: The HIRIS modular smartwatch "allows wearers to control their connected home devices using various gestures like wrist turning and clapping, as well as bunch of other things like fitness and 3D tracking." The HIRIS Tracker "allows the effortless capture of movement for specific purposes, such as analyzing ones sports form or surfing technique, aiding rehabilitation, or even animation, as well as generate precise performance metrics for health fitness and performance." HIRIS Core "is splash proof, and can be controlled by gesture commands, allowing you to take control of other technology around you such as your smartphone, smart home devices such as lighting or appliances, and even take control of a flying drone with the flick of your wrist." The modular wearable computer is "powerful enough to analyze 3D gesture movements as well as track fitness and sports performance in real time" and 
PNNL RTA Monthly Report - January 2015

Wearable Computers

customizable "to adapt to any interest with a rich library of accompanying apps now available in the HIRIS Store."

Status: Evolving

Funding: Crowdfunding

Product link: https://www.indiegogo.com/projects/hiris-the-first-wearable-computer-for-everyone

Source: HIRIS 'wearable computer': home automation control on your wrist http://www.slashgear.com/hiris-wearable-computer-home-automation-control-on-your-wrist-22365738/

HIRIS "a wearable computer, for everyone," Indiegogo Campaign Now Live http://www.realwire.com/releases/HIRIS-a-wearable-computer-for-everyone-Indiegogo-Campaign-NowLive

\subsubsection{XOEye Technology, Vuzix}

Technology name: Customized enterprise wearable technology

Description: XOEye Technology (wearable solutions company) and Vuzix (video eyewear and smart glasses) are partnering to deliver "custom, end-to-end enterprise wearable technology implementations consisting of ANSI certified smart glasses, a customized embedded Linux software platform, and advanced features and applications to manufacturing, construction, field services and other deskless industries in North America and Europe." This includes combining "Vuzix' M100 smart glasses with [the] XOLinux operating system and Vision cloud-based management and communications platform to deliver a wearable computing environment suitable for the toughest frontline work scenarios within manufacturing, construction, field services, and widely distributed organizations." The bundle "collects workplace data and images for later retrieval and analysis while facilitating project management, employee communication, on-site safety and more."

Status: Evolving

\section{Funding:}

Product link: http://www.xoeye.com/, http://www.vuzix.com/

Source: XOEye Technologies and Vuzix Partner to Deliver End-to-End Enterprise Wearable Technology Solutions in North America and Europe http://money.cnn.com/news/newsfeeds/articles/marketwire/1167245.htm 
PNNL RTA Monthly Report - January 2015

Other

\section{$10.0 \quad$ Other}

\subsubsection{Acticheck}

Technology name: Acticheck alert wristband

Description: Acticheck is a "continuously monitoring personal alert system" that tracks activity for concern (spike in temperature, unexpected movement) and then begins alerting the user. If there is no response, the wristband sends alert and GPS information to the user's network. The user can also squeeze the device in distress to signal an alert. Acticheck features a 2-year battery life.

Status: Evolving

Funding: Crowdfunding

Product link: http://acticheck.com/

Source: Wearable smartband from Saffron Walden company hopes to save lives of vulnerable people http://www.cambridge-news.co.uk/Wearable-smartband-Saffron-Walden-company-hopes/story25924925-detail/story.html

\subsubsection{ActiveProtective}

Technology name: Wearable airbag

Description: The wearable airbag is worn around the waist, and "when its onboard 3D motion sensors detect atypical motion that's unique to falling, it uses a cold gas inflator (the same type used in seatbeltmounted airbags) to deploy a slab-like airbag that runs down the sides of the hips. When the wearer hits the ground, the bag reduces impact force to the hip bones by a claimed 90 percent."

Status: Evolving - commercialization planned for 2016

\section{Funding:}

Product link: http://www.activeprotect.co/

Source: Wearable airbag designed to protect seniors when they fall http://www.gizmag.com/wearable-airbag-hip-protection/35594/ 
PNNL RTA Monthly Report - January 2015

Other

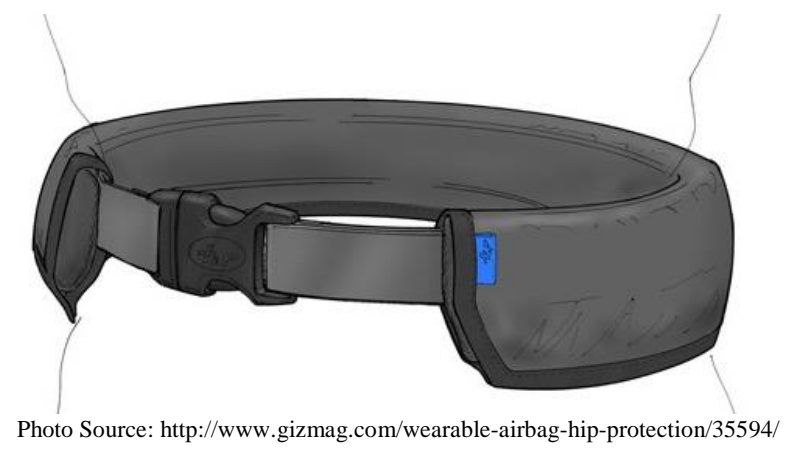

\subsubsection{BAE Systems}

Technology name: Wearable antenna

Description: BAE System was issued a patent for its "body wearable antenna." It is described in the patent as combining "a body wearable antenna adapted to be worn against the body comprising: a first antenna part; and a second antenna part insulated from the first antenna part; wherein the first antenna part is adapted to be worn circumferentially around a body part; and the second antenna part is adapted to be worn longitudinally against a body part."

Status: Evolving

\section{Funding:}

Product link: http://patft.uspto.gov/netacgi/nph-

Parser?Sect $1=$ PTO2\&Sect2=HITOFF \&p=1\&u=\%2Fnetahtml\%2FPTO\%2Fsearchbool.html\&r=1\&f=G\&l=50\&co1=AND\&d=PTXT\&s1=8933851\&OS=8933851\&RS=8933851

Source: BAE Systems: Patent Issued for Body Wearable Antenna http://www.4-traders.com/BAE-SYSTEMS-PLC-9583545/news/BAE-Systems--Patent-Issued-for-BodyWearable-Antenna-19756489/

\subsubsection{Fasetto: Link}

Technology name: Link wristband storage device

Description: Link is a wrist-worn 1-terabyte storage device, accessible over wifi. A user can stream video or files from the wristband to other devices like a tablet. The waterproof device features read-write speeds of $530 \mathrm{Mpbs}$ and $470 \mathrm{Mbps}$ respectively as well as fitness-tracking features, a 12-hour battery life of streaming video ( 2 week battery life on standby), and wireless charging.

Status: Evolving

Funding: Crowdfunding

Product link: https://www.indiegogo.com/projects/link-a-wireless-wristband-with-1tb-of-ssd-storage

Source: Fasetto's Link wearable solid state drive puts a terabyte on your wrist 
http://www.pcworld.com/article/2867325/fasettos-link-wearable-solid-state-drive-puts-a-terabyte-onyour-wrist.html

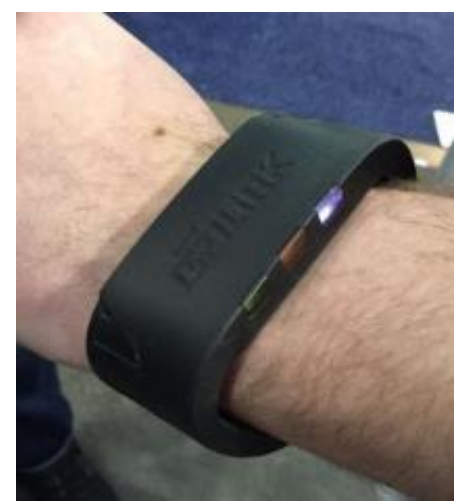

Photo Source: http://www.pcworld.com/article/2867325/fasettos-link-wearable-solid-state-drive-puts-a-terabyte-on-your-wrist.html

\subsubsection{Globalfoundires, Linear Dimensions Semiconductor Inc.}

Technology name: LND1114 14-channel reference

Description: Globalfoundires and Linear Dimensions Semiconductor Inc. are manufacturing a 14channel programmable reference "designed to meet the tuning needs of emerging [internet of things] sensors and wearable applications. The LND1114 is available in QFN-3×2.2mm form factor, and is the world's smallest programmable multi-channel reference product. With a typical drift of only $13 \mathrm{uV}$ after 10 years at $70 \mathrm{C}$, low temperature drift and an initial accuracy of $0.2 \%$, the LND1114 is ideally suited for precision sensor biasing." The developers describe the device as providing "a revolutionary new way to bias and tune precision devices," enhancing users' abilities to integrate their multitude of wearables (fitness trackers, cell phones, cameras, media players, headsets).

Status: Soon to be released

\section{Funding:}

Product link: http://globalfoundries.com/newsroom/press-releases/2015/01/09/globalfoundries-andlinear-dimensions-to-offer-joint-analog-solution-for-fast-growing-wearables-and-mems-sensors-markets

Source: GLOBALFOUNDRIES and Linear Dimensions to offer joint analog solution for wearables and MEMs sensors markets http://electroiq.com/blog/2015/01/globalfoundries-and-linear-dimensions-to-offer-joint-analog-solutionfor-wearables-and-mems-sensors-markets/

\subsubsection{GTX Corp.}

Technology name: GPS SmartSoles

Description: GTX is producing "the latest in miniaturized, low power consumption technology and offers a robust GPS and cellular location platform that enables subscribers to track in real time the whereabouts of people, pets, vehicles or high valued assets through a complete end to end - customizable GPS/GPRS transceiver module, wireless connectivity gateway, Smartphone Apps, middleware, and viewing portal." GTX is most recently producing wearable miniaturized GPS tracking solutions, specifically in shoe 
insoles, reported to help with persons of Alzheimer's, Dementia, Autism. The device features “patented Personal Location Services (PLS) platforms consist of miniaturized, always-on (Wearable GPS Technology) Assisted 2 way GPS tracking and GSM/GPRS wireless location-reporting technologies which provide continuous real-time, location coordinates rendered on Google Maps."

Status: Evolving

Funding:

Product link: www.GTXCorp.com

Source: GTX Corp. - Location-based Wearable Technology Developer

http://stocknewsnow.com/commentary/ANEWSID23012015100001/GTX-Corp-Talks-Location-basedWearable-Technology-

\subsubsection{Texas A\&M: HaptiGo}

Technology name: HaptiGo

Description: HaptiGo is "a lightweight haptic vest that provides pedestrians both navigational intelligence and obstacle detection capabilities." The device "consists of optimally-placed vibro-tactile sensors that utilize natural and small form factor interaction cues, thus emulating the invisible sensation of being passively guided towards the intended direction." The developers cite the technology as applicable to soldiers in the battlefield, allowing them navigate using only vibration feedback.

Status: Evolving

\section{Funding:}

Product link: http://faculty.cs.tamu.edu/hammond/haptigo.php

Source: HaptiGo: A navigational 'tap on the shoulder'

http://ieeexplore.ieee.org/xpls/abs_all.jsp?arnumber=6775543

\subsubsection{Intel: Curie}

Technology name: Curie module

Description: Curie is a low-powered module that can "make things like jewelry, clothing, and other accessories into smart, wearable devices." The intent of the Curie was to "to take care of many common elements involved with building a wearable gadget, thus freeing retailers and other manufacturers to focus on building the device itself." The device features Intel's Quark SE SoC chipset, Bluetooth low-energy radio, sensors and battery charger.

Status: Evolving - expected to start shipping in late 2015

\section{Funding:}

Product link: http://www.intel.com/content/www/us/en/wearables/wearable-soc.html 
PNNL RTA Monthly Report - January 2015

Other

Source: Intel's button-sized Curie module transforms any object into a smart, wearable gadget http://venturebeat.com/2015/01/06/intels-button-sized-curie-module-transforms-any-object-into-a-smartwearable-gadget/

\subsubsection{Novartis, Qualcomm Existence}

Technology name: 2net

Description: Novartis has partnered with Qualcomm Existence to use its cloud-based 2net platform to assemble medical tool information and gather medical device data during clinical trials. Novartis recently "recently launched an observational trial accumulating biometric data from chronic lung illness sufferers using smartphones linked to 2net." The platform is anticipated to "combine a few scientific units in one position, improving 'flexibility and scalability' and producing extra environment friendly, cheaper trials."

Status: Evolving

Funding: According to the press release, "The joint investment company will leverage up to $\$ 100$ million to support selected innovations."

Product link: http://www.qualcommlife.com/images/pdf/press/Qualcomm\%20VenturesNovartis\%20Press\%20Note\%20V1_forCorpclean\%20(CC)_finalPDF.pdf

Source: Novartis-Qualcomm deal leads race to bring wearable tech to pharma - OutSourcing http://www.wearable-technology.co/?p=12483

\subsubsection{Nudge}

Technology name: Nudge app

Description: Nudge "takes consumers' wearable data and creates a detailed picture of an individual's health." Nudge can track "dietary intake, level of hydration, minutes of fitness and hours of sleep" and sync with leading apps and devices (Fitbit, Strava, Moves, Up by Jawbone, etc.). The app "uses a carefully calculated, evidence-proven algorithm to present users with a Nudge Factor, an indexed number representing the overall level of health of the user, which can be used for comparison with other Nudge users and friends on social media, regardless of apps and trackers used."

Status: Evolving

\section{Funding:}

Product link: http://www.nudgeyourself.com/

Source: Wearable Health Data Curator Nudge Launches New App Features http://hitconsultant.net/2015/01/21/wearable-health-data-curator-nudge-new-app-features/

\subsubsection{Quantum Functional Semiconductor Research Center}

Technology name: Conductive carbon nanotube functionalized fabric 
Description: This research explores "Highly efficient [carbon nanotube] functionalized cotton fabrics for flexible/wearable heating applications." Cotton fabrics were combined with walled carbon nanotubes through dip-coating. Researchers studied electrothermal performances of the devices in terms of applied voltage, heating rate and input power density. The highly flexible heater on uniformly interconnected carbon nanotube networks yields an effective, rapid, and low-power heating. The results have "promising applications of these devices in wearable electronics and beyond and could be woven into the textile materials also."

Status: Evolving

Funding: Supported by Leading Foreign Research Institute Recruitment Program through the National Research Foundation of Korea funded by the Ministry of Education, Science and Technology (no. 2014039452).

Research link: http://dx.doi.org/10.1039/C4RA10667A

Source: Highly efficient CNT functionalized cotton fabrics for flexible/wearable heating applications http://pubs.rsc.org/en/content/articlehtml/2015/ra/c4ra10667a

\subsubsection{Safeti}

Technology name: Personal security device

Description: Safeti is a device that when activated, sends a distress message to your "personal security concierge," including specific contacts, with your location and status. The device does not require Bluetooth but rather uses 2-way GPS communication to allow the concierge to follow the user. When activated, the Safeti concierge can then contact your contacts and call 911 if necessary. The device is waterproof, does not require connection to a smart device, and features a battery life of up to a year. The device's "patent pending Trio Core technology incorporates GPS, GPRS and Wi-Fi triangulation into a single chipset" to track the user.

Status: Evolving

Funding: Crowdfunding

Product link: https://www.indiegogo.com/projects/safeti-your-on-demand-personal-safety-concierge

Source: Safeti is your on-demand safety concierge to keep your friends and family safe. https://www.indiegogo.com/projects/safeti-your-on-demand-personal-safety-concierge 
PNNL RTA Monthly Report - January 2015

Other

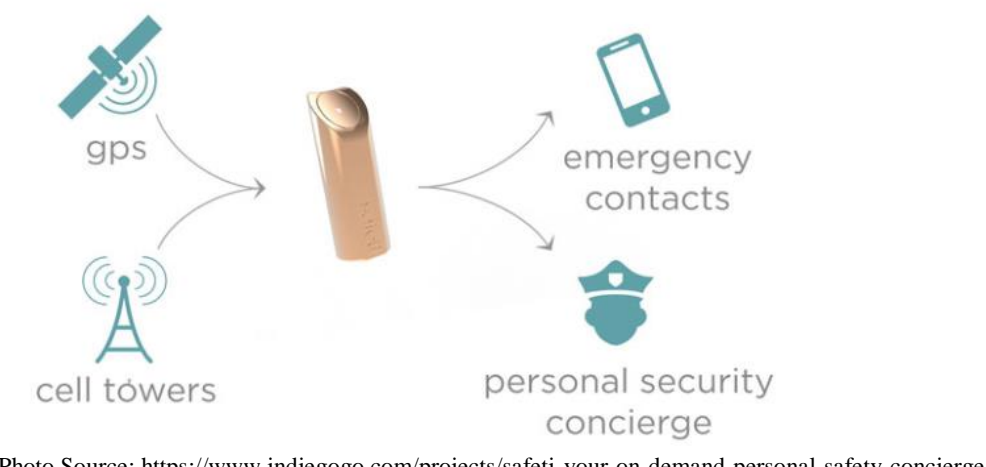

\subsubsection{SkyTraq: Venus828F}

Technology name: Venus828F multi- Global Navigation Satellite System (GNSS) receiver

Description: The SkyTraq Venus828F multi-GNSS receiver module was designed with wearables in mind and with the ability to communicate with multiple satellite systems and track up to 28 satellites concurrently. This "stand-alone multi-GNSS receiver module in a compact $7 \mathrm{~mm} \times 7 \mathrm{~mm}$ form factor" and "integrates all the necessary components forming a complete working GNSS receiver, including GNSS chipset, 0.5ppm TCXO, Flash memory, LDO regulator, DC/DC switching regulator, and passive components." Additionally, it requires an "external antenna and power supply to output accurate position / velocity / time information in standard NMEA-0183 format; enabling ease of use and fast time to market.

Status: Evolving

\section{Funding:}

Product link: http://www.skytraq.com.tw/news/news2015Jan13.html

Source: SkyTraq - Multi-GNSS receiver module with sensor hub Function for wearable and internet of things applications http://www.electropages.com/2015/01/skytraq-multi-gnss-receiver-module-sensor-hub-functionwearable-iot-applications/

\subsubsection{Stanford University}

Technology name: Nanowire Fabric

Description: Researchers are developing insulating fabric that they propose "could be a solution to the large amounts of greenhouse gases created by wintertime indoor heating." The new nanowire fabric can "insulate against conduction and convection, prevent loss of infrared radiation, allow moisture to escape, and even actively heat up with the help of a battery." The goal was for a metallic layer to reflect infrared radiation back towards the body while also allowing moisture to escape. The fabric "provides $21 \%$ more thermal insulation than normal cloth" and the researchers estimate that "With the combination of passive insulation and active heating ... about $350 \mathrm{~W}$ per person could be saved by wearing clothes made out of their nanowire fabric, instead of heating an entire room on a cold winter day." 
Status: Evolving

Funding:

Product link:

Source: A Wearable Furnace: Keeping Toasty Warm With Nanowire Fabric http://www.physicscentral.com/buzz/blog/index.cfm?postid=9216029678601772689

\subsubsection{Sussex Sensor Technology Research Centre}

Technology name: Flexible electronic circuits

Description: These flexible electronic circuits can reportedly be used in "bendable phones, smart clothing and sensory skin for prosthetic limbs." The flexibility of the material could allow devices to be rolled up and conveniently stored. The circuits are fabricated on a thin plastic foil: "By using indium gallium zinc oxide rather than silicon as a semiconductor, [the developer] was able to develop circuits that can be produced on a large scale while retaining a high level of performance." Such materials can be woven into textiles, creating clothing that can "measure data such as temperature and blood oxygenation."

Status: Evolving

\section{Funding:}

Product link:

Source: Sussex scientist wins award for research into flexible, wearable technology http://www.sussex.ac.uk/staff/newsandevents/?id=28743

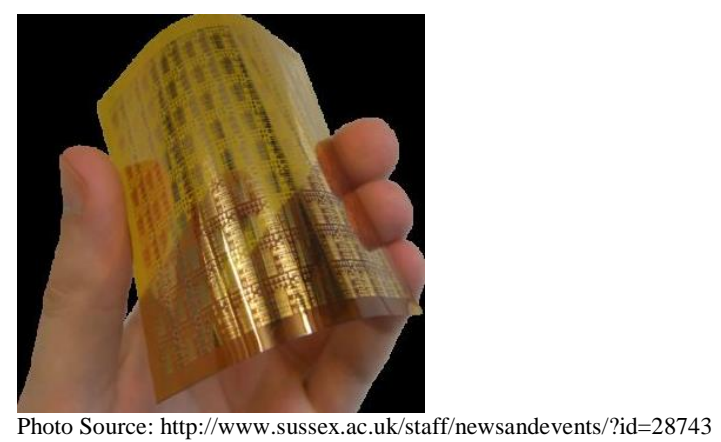

\subsubsection{Texas A\&M: GeoTrooper}

\section{Technology name: GeoTrooper}

Description: This device was designed to aid soldiers in navigation and assembly of critical tasks in the battlefield: "To facilitate the re-assembly and coordination of airborne paratrooper teams, [researchers] developed a location-aware system that uses an ad-hoc Wi-Fi network in order to broadcast and receive GPS coordinates of equipment and/or rendezvous points. The system consists of beacons, ruggedized computers placed at assembly points that broadcast their position over Wi-Fi, and receivers, handheld Android devices which orient the user towards the beacons and/or any predetermined coordinates." 
According to the Texas A\&M web site, the system was designed to be "a multi-modal mobile navigation system that uses ruggedized beacons to mark assembly points and heavy drop equipment and smartphones to assist in navigating to these points while minimizing cognitive load and maximizing situational awareness."

Status: Available - In use by the military

Funding: The project received funds from DARPA IPTO program and equipment donated from the Rockwell Collins Charitable Corporation program.

Product link:

Source: GeoTrooper: a mobile location-aware system for team coordination http://www.researchgate.net/publication/262253522_GeoTrooper_a_mobile_locationaware_system_for_team_coordination

\subsubsection{Venture Heat}

Technology name: Wearable Cooling Technology

Description: Wearable Cooling Technology apparel "reduces moisture and keeps you cool." The garments feature "slim built-in ventilation fans under the arms. Its special honey-combed construction membrane creates airways that allow flow throughout the entire garment. The flowing air accelerates the evaporation of your body's perspiration. This process creates cooling sensation and lowers the core temperature. Summer comfort increase productivity and reduces the risk of heat fatigue." The garments' system runs on a USB Power Bank common to most smartphone users.

Status: Evolving

\section{Funding:}

Product link: $\underline{\text { http://www.ventureheat.com/ }}$

Source: Venture Heat announces apparel with Wearable Cooling Technology http://www.worldgolf.com/newswire/browse/88113-Venture-Heat-Cooling-Apparel

\subsubsection{Wi2Wi Corporation: W2SG0021i}

Technology name: W2SG0021i, a miniature GNSS module

Description: The W2SG0021i is miniature GNSS module and "high-sensitivity, low-power stand-alone receiver designed for portable applications. It can concurrently track multiple satellite constellations (GPS, GLONASS, BDS, SBAS, and is Galileo-ready) and has ultra-fast time-to-first-fix, a small form factor, and high receive sensitivity for a broad spectrum of OEM products, including machine-to-machine (M2M) and consumer wearables." Compared to most devices, this module offers three ways of communicating: GNSS, Wi-Fi, and Bluetooth solutions.

Status: Evolving - samples and development kit will be available in Q1 2015

\section{Funding:}


PNNL RTA Monthly Report - January 2015

Other

Product link: http://www.wi2wi.com/

Source: Wi2Wi Offers GNSS Module for M2M and Wearable Markets

http://gpsworld.com/wi2wi-offers-gnss-module-for-m2m-and-wearable-markets/ 
PNNL RTA Monthly Report - January 2015

Appendix A: Technology Summary

\section{Appendix A}

\section{Technology Summary}


PNNL RTA Monthly Report - January 2015

Appendix A: Technology Summary

\section{Appendix A}

\section{Technology Summary}

The following spreadsheet provides a summary of the technologies compiled in this report. For an electronic copy, please contact Jaki Upton at jaki.upton@pnnl.gov. This information is not meant to be an exhaustive list nor an endorsement of any technology described herein. 
PNNL RTA Monthly Report - January 2015

Appendix A: Technology Summary

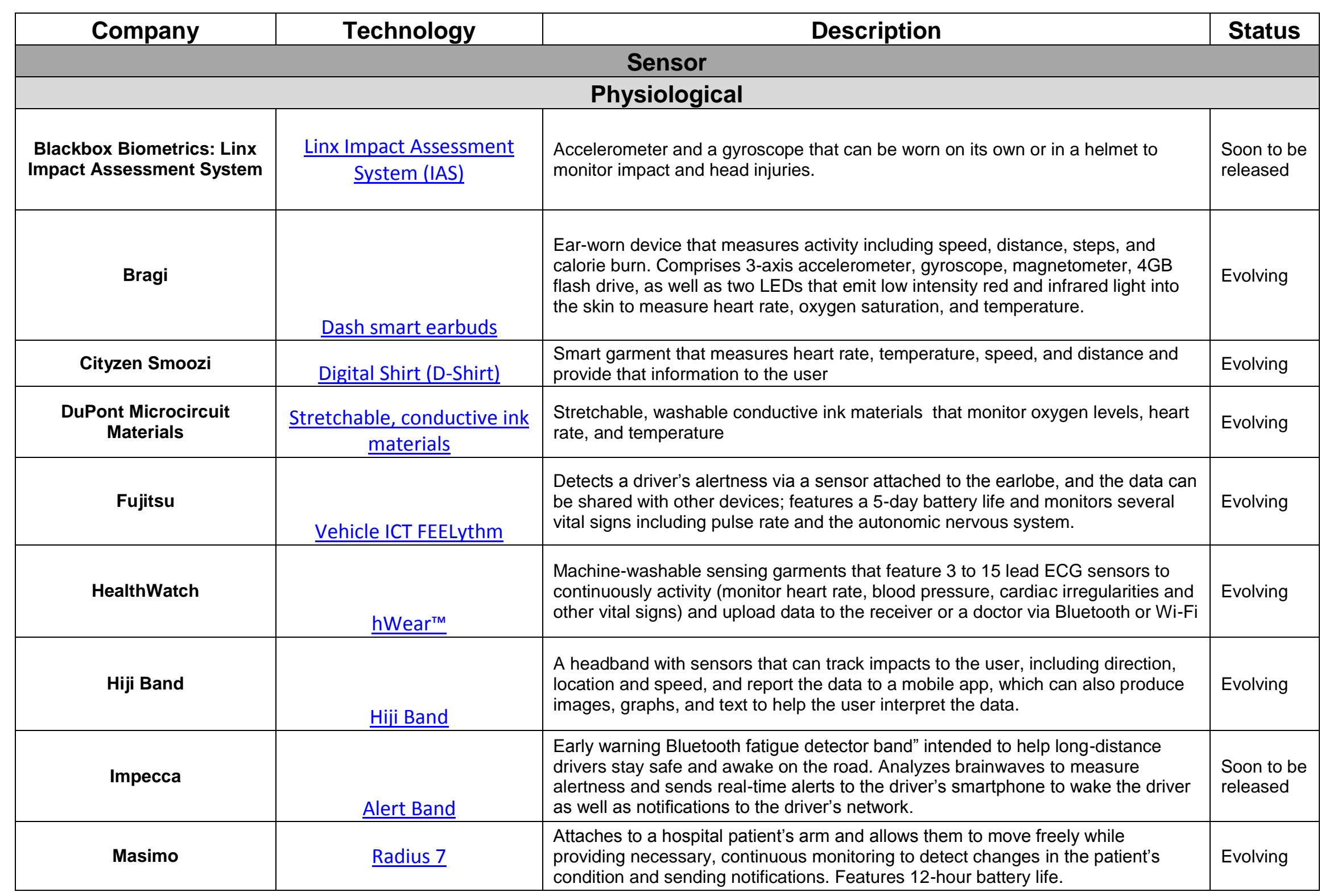


PNNL RTA Monthly Report - January 2015

Appendix A: Technology Summary

\begin{tabular}{|c|c|c|c|}
\hline Company & Technology & Description & Status \\
\hline MiTAC & MiracleBand & $\begin{array}{l}\text { Allows a user to track and analyze physiological conditions including sleep } \\
\text { patterns and exercise; employs 2-minute ECG detection. }\end{array}$ & Evolving \\
\hline $\begin{array}{l}\text { North Carolina State } \\
\text { University }\end{array}$ & Wearable sensor & $\begin{array}{l}\text { Uses silver nanowires to monitor electrophysiological signals, such as } \\
\text { electrocardiography (EKG) or electromyography (EMG). Comparable to wet } \\
\text { electrodes but provides longer-term monitoring and improvec accuracy. }\end{array}$ & Evolving \\
\hline Plantronics & Concept 2 & $\begin{array}{l}\text { Ear-worn device that offers a sensor and motion-tracking capabilities. Can track } \\
\text { head and body movements in 3-D space. The can be used to wirelessly unlock a } \\
\text { door using voice commands, wirelessly connect to a smart device in a remote } \\
\text { location. }\end{array}$ & Evolving \\
\hline Samsung & $\begin{array}{c}\text { Early Detection Sensor \& } \\
\text { Algorithm Package (EDSAP) }\end{array}$ & $\begin{array}{l}\text { A headset with sensors that collect and transmit brainwave data to a mobile app, } \\
\text { where algorithms analyze the brainwaves and determines the likelihood of a } \\
\text { stroke within a } 60 \text {-second time span. }\end{array}$ & Evolving \\
\hline SensiumVitals & $\underline{\text { SensiumVitals }}$ & $\begin{array}{l}\text { Light-weight, wearable, wireless single patient use patch that takes a patient's } \\
\text { vital signs (heart rate, respiration, temperature) every two minutes and can } \\
\text { communicate the information to the patient's physician. }\end{array}$ & Evolving \\
\hline Temptraq & $\begin{array}{l}\text { Temptraq wearable } \\
\text { thermometer patch }\end{array}$ & $\begin{array}{l}\text { Wearable soft-patch thermometer that allows a user to track body temperature for } \\
\text { up to } 24 \text { hours via Bluetooth and a smartphone app. }\end{array}$ & Evolving \\
\hline $\begin{array}{l}\text { University of California San } \\
\text { Diego Center for Wearable } \\
\text { Sensors }\end{array}$ & $\frac{\text { Paper-based "tattoo" }}{\text { glucose monitor }}$ & $\begin{array}{l}\text { Paper-based temporary tattoo that adheres to the skin and measures a user's } \\
\text { glucose. It also uses electrodes to zap skin to indicate levels that are out of the } \\
\text { intended range. }\end{array}$ & Evolving \\
\hline $\begin{array}{l}\text { University of Maryland, } \\
\text { Microsoft }\end{array}$ & SWARM smart scarf & $\begin{array}{l}\text { Conductive fabric circuity in this "smart scarf" comprises a series of modules that } \\
\text { can heat up and vibrate and are controlled via smart phone over Bluetooth. }\end{array}$ & Evolving \\
\hline Zensorium & $\underline{\text { Being activity tracker }}$ & $\begin{array}{l}\text { a smart wristband (or clip) that can track NREM and REM sleep, heart rate, steps, } \\
\text { calorie burn, distance, speed, and mood (Distress, Excited, Normal and Calm), } \\
\text { which it figures by measuring heart rate and blood pressure. Battery life of } 2-3 \\
\text { days and OLED touchscreen display. }\end{array}$ & Evolving \\
\hline \multicolumn{4}{|c|}{ Other } \\
\hline Amulet Corp. & $\frac{\text { Scarab wearable sensor }}{\text { platform }}$ & $\begin{array}{l}\text { Allows the user to continuously monitor their environment and communicate "local } \\
\text { conditions and hidden dangers" via smartphone to the web and the user's } \\
\text { contacts. The device utilizes mobile apps, an online mapping service to play } \\
\text { sensor impressions (i.e., Google Maps), and the user's selected community of } \\
\text { contacts. }\end{array}$ & Evolving \\
\hline $\begin{array}{l}\text { John Knollmeyer, Timotius } \\
\text { Sitorus, Kushagra Pundeer } \\
\text { (individuals }\end{array}$ & $\frac{\text { Ultrasonic obstacle }}{\text { detector }}$ & $\begin{array}{l}\text { Head-mounted ultrasonic rangefinder with variable feedback for obstacle } \\
\text { detection" that gives a user with limited or no vision the ability to detect the } \\
\text { distance and direction of obstructions, giving them the ability to determine } \\
\text { obstructions in their environment without having to physically feel them. }\end{array}$ & Evolving \\
\hline
\end{tabular}


PNNL RTA Monthly Report - January 2015 Appendix A: Technology Summary

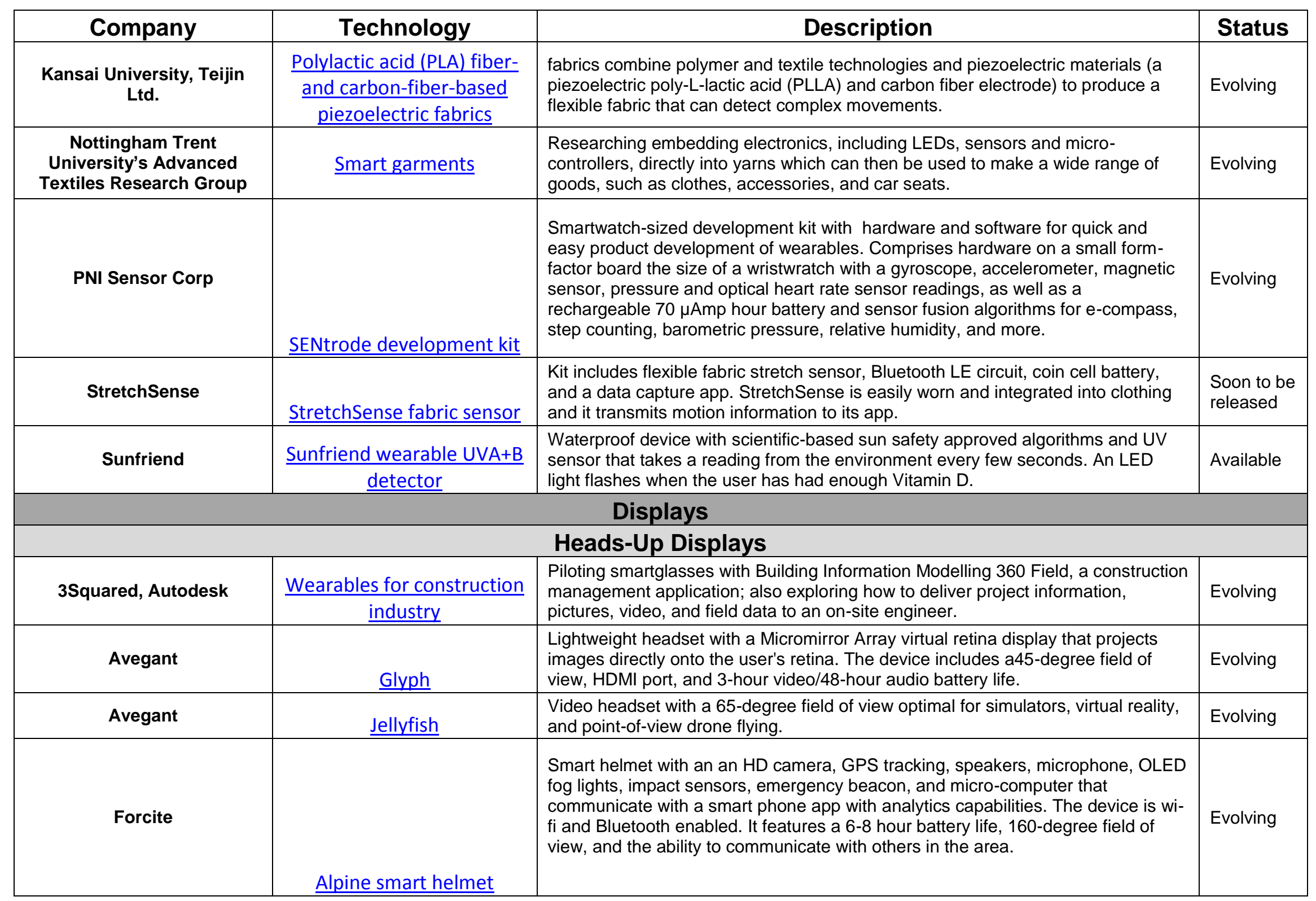


PNNL RTA Monthly Report - January 2015 Appendix A: Technology Summary

\begin{tabular}{|c|c|c|c|}
\hline Company & Technology & Description & Status \\
\hline Microsoft & HoloLens & $\begin{array}{l}\text { Glasses that project holographic displays onto surfaces around the user. It does } \\
\text { not require cables or use of a secondary device. }\end{array}$ & $\begin{array}{l}\text { Soon to be } \\
\text { released }\end{array}$ \\
\hline Moggles & $\frac{\text { Moggles virtual reality }}{\text { system }}$ & $\begin{array}{l}\text { Virtual reality system that uses display and motion sensors a smartphone and } \\
\text { tracks the motions of the user's head and updates the viewport of the phone } \\
\text { screen }\end{array}$ & Evolving \\
\hline Osaka & $\begin{array}{l}\text { Intelligent text } \\
\text { management system }\end{array}$ & $\begin{array}{l}\text { Researchers are using camera tracking to recognize a route on which the user is } \\
\text { traveling and move text from one viable location to the next to maximize } \\
\text { readability. The research aims to help readability of text on see-through heads-up } \\
\text { displays. }\end{array}$ & Evolving \\
\hline Syndiant & Head-mounted display & $\begin{array}{l}\text { Optical modules for head-mounted displays that are fixed focus, light weight, and } \\
\text { low-power consuming with integrated RGB LED illumination }\end{array}$ & Evolving \\
\hline Toshiba & Toshiba Glass & Projects the display directly onto the lens and wherever the user is looking. & Evolving \\
\hline Vuzix & Next-generation optics & $\begin{array}{l}\text { Developing next generation fashion-based wearable display products into the } \\
\text { consumer market }\end{array}$ & Evolving \\
\hline \multicolumn{4}{|c|}{ Power } \\
\hline \multicolumn{4}{|c|}{ Self-Powering (Harvesting) } \\
\hline $\begin{array}{l}\text { Hahn-Schickard- } \\
\text { Gesellschaft Institute for } \\
\text { Micromachining and } \\
\text { Information Technology }\end{array}$ & $\frac{\text { Shock and swing shoe- }}{\text { worn harvesters }}$ & $\begin{array}{l}\text { Generates power when the heel of a shoe strikes the ground whilst the so-called } \\
\text { swing harvester generates power when the foot is swinging }\end{array}$ & Evolving \\
\hline $\begin{array}{l}\text { Korea Advanced Institute of } \\
\text { Science and Technology } \\
\text { TEGway }\end{array}$ & Wearable thermos-element & $\begin{array}{l}\text { Generates electricity from human body heat and is light and thin to easily put on } \\
\text { clothes or integrated into devices generating waste heats such as many } \\
\text { equipment in cars, planes and factories. }\end{array}$ & Evolving \\
\hline $\begin{array}{l}\text { Korea Advanced Institute of } \\
\text { Science and Technology }\end{array}$ & $\frac{\text { ZnO piezoelectric micro }}{\frac{\text { energy harvesters }}{\text { "nanogenerators" }}}$ & $\begin{array}{l}\text { Small energy harvesters made up of piezoelectric } \mathrm{ZnO} \text { nanorod or nanowire } \\
\text { arrays sandwiched between two electrodes formed on the flexible substrates that } \\
\text { are highly energy efficient and fit for self-powered sources and sensor devices. }\end{array}$ & Evolving \\
\hline $\begin{array}{l}\text { Korea Institute of Science } \\
\text { and Technology }\end{array}$ & $\frac{\text { Flexible, self-powered }}{\text { piezoelectric sensor }}$ & $\begin{array}{l}\text { Highly-stretchable piezoelectric hemispheres composed of composite thin-film } \\
\text { nanogenerators fabricated as a self-powered, exceptionally sensitive sensor for } \\
\text { providing sensitive motion information from a human body }\end{array}$ & Evolving \\
\hline $\begin{array}{l}\text { National University of } \\
\text { Singapore }\end{array}$ & Flexible generators & $\begin{array}{l}\text { Small, flexible generators that convert muscle movements or friction-inducing } \\
\text { motion into power (turning mechanical energy into electrical energy). }\end{array}$ & Evolving \\
\hline $\begin{array}{l}\text { Sogang University Micro \& } \\
\text { Nano Engineering } \\
\text { Laboratory }\end{array}$ & $\frac{\text { Body motion energy }}{\text { harvester }}$ & $\begin{array}{l}\text { Flexible, elastic body motion energy harvester to be applied to high-flexion joints } \\
\text { and suitable for integration with fabrics. }\end{array}$ & Evolving \\
\hline \multicolumn{4}{|c|}{ Power Supplies } \\
\hline
\end{tabular}


PNNL RTA Monthly Report - January 2015 Appendix A: Technology Summary

\begin{tabular}{|c|c|c|c|}
\hline Company & Technology & Description & Status \\
\hline Imprint Energy & ZincPoly $^{\mathrm{TM}}$ & $\begin{array}{l}\text { Printed, ultrathin, flexible, high energy density, rechargeable batteries created with } \\
\text { non-toxic, non-volatile materials. }\end{array}$ & Evolving \\
\hline Jenax & Foldable battery & $\begin{array}{l}\text { Foldable batter that can tolerate } 1,000,000 \text { times bending in its complete life } \\
\text { cycle, withstand extreme temperatures, and thickness ranging from } 35-20 \mathrm{~cm} \\
\text { depending the end product. }\end{array}$ & Evolving \\
\hline Rice University & Supercapacitors & $\begin{array}{l}\text { Used laser-induced graphene to produce supercapacitors, energy-storage } \\
\text { devices for use in wearables. The vertically-stacked supercapacitors showed } \\
\text { almost no change in electrical performance when flexed, even after } 8,000 \text { bending } \\
\text { cycles. }\end{array}$ & Evolving \\
\hline Toes Opto-Mechatronics & $\underline{\text { Thin-film lithium battery }}$ & $\begin{array}{l}\text { Thin-film batteries delivering the safety, ultra-thinness, flexibility, and high capacity } \\
\text { fit for smart cards and wearable technologies. }\end{array}$ & Evolving \\
\hline University of Central Florida & $\begin{array}{l}\text { Energy-storing and energy- } \\
\frac{\text { conducting super capacitor }}{\underline{\text { wire }}}\end{array}$ & $\begin{array}{l}\text { a single wire that both conducts and stores electricity. The super capacitor } \\
\text { wrapped around the wire can store the energy at the same time as transmitting it. } \\
\text { Proposed to increase lithium ion battery life from an average of } 1,000 \\
\text { charge/discharge cycles to nearly } 1 \text { million. }\end{array}$ & Evolving \\
\hline \multicolumn{4}{|c|}{ Communications } \\
\hline \multicolumn{4}{|c|}{ Hands-Free Operations } \\
\hline Fujitsu Laboratories Ltd & $\frac{\text { Near-field communications }}{\text { ring }}$ & $\begin{array}{l}\text { Compact and lightweight wearable ring that offers handwriting-input functionality } \\
\text { and serves as a reader for near-field communications tags. }\end{array}$ & Evolving \\
\hline & $\underline{\text { Ring }}$ & $\begin{array}{l}\text { Allows the user to control smart devices (within a 2-meter radius) via Bluetooth } \\
\text { using gestures. }\end{array}$ & Evolving \\
\hline Thalmic Labs & Myo armband & $\begin{array}{l}\text { Muscle-sensing gesture control armband with eight muscle-sensing modules that } \\
\text { strap onto the widest part of the forearm, which then lets the device detect and } \\
\text { interpret hand gestures. }\end{array}$ & Available \\
\hline Thanko & Wearable mouse & $\begin{array}{l}\text { Glove-like device with an integrated sensor that sits atop your hand and is } \\
\text { connected through a wire to two buttons, which would fit onto your index finger. } \\
\text { The device allows the wearer to control a smart device by maneuvering their hand } \\
\text { like that of using a mouse. }\end{array}$ & Available \\
\hline \multicolumn{4}{|c|}{ Short-Range, Low-Power Bluetooth } \\
\hline Cynaps & $\underline{\text { Mint 3-D printed headset }}$ & $\begin{array}{l}\text { Produces audio through vibration, via Bluetooth from a smart phone, tablet, PC } \\
\text { and many smartwatches and without blocking the user's ears. The modules are } \\
\text { modifiable to fit hats, helmets, goggles, etc. }\end{array}$ & Available \\
\hline TOG & $\frac{\text { TOG Bluetooth-enabled }}{\text { open-source button }}$ & $\begin{array}{l}\text { Ultra- small Bluetooth-enabled open-source button that is slightly larger than a } \\
\text { microSD cardand can remotely control Bluetooth-enabled devices }\end{array}$ & Evolving \\
\hline \multicolumn{4}{|c|}{ Cameras } \\
\hline
\end{tabular}


PNNL RTA Monthly Report - January 2015

Appendix A: Technology Summary

\begin{tabular}{|c|c|c|c|}
\hline Company & Technology & Description & Status \\
\hline Ambarella, Inc. & $\frac{\text { A12W Wearable Security }}{\text { Reference Design Kit }}$ & $\begin{array}{l}\text { Enables fast development of compact, ultra low-power, body-worn HD video } \\
\text { cameras suitable for police and security applications. Includes the A12W ultra } \\
\text { low-power HD camera System-On-Chip can encode a Full HD } 1080 \text { p30 video } \\
\text { stream and a second HD stream for dual lens camera designs with wireless } \\
\text { streaming. }\end{array}$ & Available \\
\hline Apple & $\frac{\text { Wearable action camera }}{\underline{\text { system }}}$ & $\begin{array}{l}\text { Wearable action digital camera system with an image capture module and a } \\
\text { remote control module. }\end{array}$ & Evolving \\
\hline Hammacher & $\frac{\text { Video-recording wifi }}{\underline{\text { sunglasses }}}$ & $\begin{array}{l}\text { Sunglasses with video capability (63-degree angle, } 1080 \mathrm{p} \times 1920 \text { high-definition } \\
\text { video at } 30 \text { frames per second), photo capability, the ability to record video and } \\
\text { transfer it to a smartphone, and a battery life of } 60 \text { minutes - as well as UV } \\
\text { protection of traditional sunglasses. }\end{array}$ & Available \\
\hline HTC & $\underline{\mathrm{RE}}$ wearable camera & $\begin{array}{l}\text { provides distraction-free video and photo capture. Offers easy-to-use one-button } \\
\text { operation and 146-degree wide-angle lens. }\end{array}$ & Available \\
\hline Geco & $\underline{\text { Geco camera }}$ & $\begin{array}{l}\text { Easy-to-use camera with a single tactile button to operate, a } 100 \text { degree viewing, } \\
\text { weighs only } 20 \text { grams, mounts easily, and has an approximately } 45 \text { minutes to } 1 \\
\text { hour battery life. }\end{array}$ & Evolving \\
\hline GoPro & Hero 3 Black Edition & $\begin{array}{l}\text { GoPro with an f. stop of } 2.8 \text {, an improved speed on the wifi chip, making remote } \\
\text { control and streaming more seamless than ever. Offers } 30 \% \text { increase in battery } \\
\text { capacity and new SuperView ultra wide screen feature. }\end{array}$ & Available \\
\hline GoPro, Vislink & $\frac{\text { Live broadcast system for }}{\text { GoPro cameras }}$ & GoPro cameras with live broadcast system & Evolving \\
\hline iON & Snapcam & $\begin{array}{l}\text { A 1.5-inch clip-on "lifelogging" 8-megapixel camera with HD video capabilities, } \\
\text { wifi/Bluetooth streaming capabilities, and a battery life of } 1 \text { week in standby, } 2 \\
\text { hours of HD video shooting, or } 5,000 \text { photos per charge. }\end{array}$ & $\begin{array}{l}\text { Soon to be } \\
\text { released }\end{array}$ \\
\hline $\begin{array}{l}\text { Lifelogger Technologies } \\
\text { Corp }\end{array}$ & $\underline{\text { Lifelogger }}$ & $\begin{array}{l}\text { Hands-free, 5-megapixel wearable video camera that combines video, voice, text, } \\
\text { and facial recognition into the camera, to fully immerse the user and others into a } \\
\text { point of view experience. Links to Lifelogger cloud system. }\end{array}$ & Evolving \\
\hline Liquid Image & Ego LS wearable 4G camera & $\begin{array}{l}\text { Integrates live transmission streaming metadata from connected devices such as } \\
\text { biometrics, geolocation, and other sensor information. Includes } 135 \text {-degree } \\
\text { camera angle and } 4 G \text { LTE, Wi-Fi, Bluetooth, and low frequency radiofrequency, } \\
\text { with the option to use public or private networks. }\end{array}$ & $\begin{array}{l}\text { Soon to be } \\
\text { released }\end{array}$ \\
\hline m-View, FireCam & $\frac{\text { Fire Cam with streaming }}{\text { capability }}$ & $\begin{array}{l}\text { Rugged, heat-resistant camera with video streaming system. The Wi-Fi pro } \\
\text { camera attaches to any shirt, vest or coat; can record high definition 1080p; and } \\
\text { offers a 150-degree wide angle lens, LED light, and infrared light. }\end{array}$ & Available \\
\hline
\end{tabular}


PNNL RTA Monthly Report - January 2015 Appendix A: Technology Summary

\begin{tabular}{|c|c|c|c|}
\hline Company & Technology & Description & Status \\
\hline Narrative & $\frac{\text { Narrative Clip } 2 \text { lifelogging }}{\text { camera }}$ & $\begin{array}{l}\text { Lifelogging camera with a flexible mount, 9-megapixel, 90-degree angle unit with } \\
\text { wifi and Bluetooth capability to sync images to a smart phone or Narrative's online } \\
\text { systems. }\end{array}$ & $\begin{array}{l}\text { Soon to be } \\
\text { released }\end{array}$ \\
\hline Panasonic & $\frac{\text { A500 4K mountable sports }}{\text { camera, virtual reality }}$ & $\begin{array}{l}\text { Durable, wearable camera that is water- and dust-proof, with } 4 \mathrm{k} \text { resolution at } 30 \mathrm{p} \\
\text { and built-in LCD. }\end{array}$ & Available \\
\hline TASER, EVIDENCE.com & $\begin{array}{l}\frac{\text { Body-worn video camera }}{\text { and cloud-based digital }} \\
\frac{\text { evidence management }}{\text { system }}\end{array}$ & $\begin{array}{l}\text { The body-worn AXON cameras attach to glasses, hats, collars, etc., and feature } \\
\text { wide-angle, full-color view and a pocket-size battery pack; the footage is uploaded } \\
\text { via a docking station to cloud-based EVIDENCE.com. }\end{array}$ & Available \\
\hline \multicolumn{4}{|c|}{ Breathing Apparatus } \\
\hline MSA Safety Inc. & $\begin{array}{l}\underline{\text { G1 self-contained }} \\
\underline{\text { breathing apparatus }}\end{array}$ & $\begin{array}{l}\text { Equipment includes a 50-foot bail-out cable, electronic communications } \\
\text { technology, improved vision and mobility, air cylinders are lighter and contain } 15 \\
\text { minutes more air, electronics incorporated into air regulators and communication } \\
\text { equipment, heads-up displays on the mask for better communications between } \\
\text { firefighters, and telemetry systems that allow monitoring and control by } \\
\text { commanders. }\end{array}$ & Available \\
\hline Scott Safety & $\frac{\text { Air-Pak X3 self-contained }}{\underline{\text { breathing apparatus }}}$ & $\begin{array}{l}\text { Breathing apparatus that offers a slimmer, comfortable design as well as air } \\
\text { cylinders with } 45 \text { minutes of capacity. Weighs } 10 \% \text { less than its predecessor. The } \\
\text { device's AV- } 3000 \text { HT face features a visor tested to withstand up to } 500 \text { degrees. }\end{array}$ & Available \\
\hline \multicolumn{4}{|c|}{ Exoskeleton } \\
\hline Ritsumeikan University & $\underline{\text { Passive elements }}$ & $\begin{array}{l}\text { Lighter, smaller, and softer passive elements with potential applications to create } \\
\text { wearable robots. }\end{array}$ & Evolving \\
\hline \multicolumn{4}{|c|}{ Wearable Computers } \\
\hline Arduboy & $\underline{\text { Ö Bluetooth Ring }}$ & $\begin{array}{l}\text { Ring with a 3D-printed body, a } 64 \times 32 \text { monochrome OLED display, and fully } \\
\text { functional touch button. Powered by a NRF } 51822 \text { chip set with the ability to } \\
\text { receive and reply to notifications sent via Bluetooth from a smartphone, as well as } \\
\text { display various animations. Four-hour battery life when turned on, up to } 24 \text { hours } \\
\text { on standby. }\end{array}$ & Evolving \\
\hline $\begin{array}{l}\text { Human Interactive Reliable } \\
\text { Integrated Smart Watch } \\
\text { (HIRIS) }\end{array}$ & $\frac{\text { Human Interactive Reliable }}{\frac{\text { Integrated Smart Watch }}{\underline{\text { (HIRIS) }}}}$ & $\begin{array}{l}\text { A smart watch that allows wearers to control their connected home devices using } \\
\text { various gestures like wrist turning and clapping, as well as bunch of other things } \\
\text { like fitness and 3D tracking. }\end{array}$ & Evolving \\
\hline
\end{tabular}


PNNL RTA Monthly Report - January 2015

Appendix A: Technology Summary

\begin{tabular}{|c|c|c|c|}
\hline Company & Technology & Description & Status \\
\hline XOEye Technology, Vuzix & $\frac{\text { Customized enterprise }}{\underline{\text { wearable technology }}}$ & $\begin{array}{l}\text { Combining Vuzix' M100 smart glasses with XOLinux operating system and Vision } \\
\text { cloud-based management and communications platform to deliver a wearable } \\
\text { computing environment suitable for the toughest frontline work scenarios within } \\
\text { manufacturing, construction, field services, and widely distributed organizations. }\end{array}$ & Evolving \\
\hline \multicolumn{4}{|c|}{ Other } \\
\hline Acticheck & Acticheck alert wristband & $\begin{array}{l}\text { Continuously monitoring personal alert system that tracks activity for concern } \\
\text { (spike in temperature, unexpected movement) and then begins alerting the user. If } \\
\text { there is no response, the wristband sends alert and GPS information to the user's } \\
\text { network. features a 2-year battery life. }\end{array}$ & Evolving \\
\hline ActiveProtective & $\underline{\text { Wearable airbag }}$ & $\begin{array}{l}\text { Airbag belt that is worn around the waist, activates when its onboard 3D motion } \\
\text { sensors detect atypical motion. When the wearer hits the ground, the bag reduces } \\
\text { impact force to the hip bones by a claimed } 90 \text { percent. }\end{array}$ & Evolving \\
\hline BAE Systems & Wearable antenna & An antenna adapted to be worn against the body & Evolving \\
\hline Fasetto & $\begin{array}{l}\text { Link wristband storage } \\
\text { device }\end{array}$ & $\begin{array}{l}\text { Wrist-worn 1-terabyte storage device, accessible over wifi. A user can stream } \\
\text { video or files from the wristband to other devices like a tablet. }\end{array}$ & Evolving \\
\hline $\begin{array}{l}\text { Globalfoundires, Linear } \\
\text { Dimensions Semiconductor } \\
\text { Inc. }\end{array}$ & $\frac{\text { LND1114 14-channel }}{\text { reference }}$ & $\begin{array}{l}\text { A 14-channel programmable reference product intended for integrating wearables, } \\
\text { featuring QFN-3×2.2mm form factor, with a typical drift of only } 13 \mathrm{uV} \text { after } 10 \text { years } \\
\text { at } 70 \mathrm{C} \text {, low temperature drift and fit for precision sensor biasing. }\end{array}$ & $\begin{array}{l}\text { Soon to be } \\
\text { released }\end{array}$ \\
\hline GTX Corp. & $\underline{\text { GPS SmartSoles }}$ & $\begin{array}{l}\text { Shoe insoles that include patented Personal Location Services (PLS) platforms } \\
\text { with miniaturized, always-on (Wearable GPS Technology) Assisted } 2 \text { way GPS } \\
\text { tracking and GSM/GPRS wireless location-reporting technologies which provide } \\
\text { continuous real-time, location coordinates rendered on Google Maps }\end{array}$ & Evolving \\
\hline Texas A\&M & $\underline{\text { HaptiGo }}$ & $\begin{array}{l}\text { Lightweight haptic vest that provides both navigational intelligence and obstacle } \\
\text { detection capabilities, helping the wearer to navigate with only vibrotactile } \\
\text { feedback. }\end{array}$ & Evolving \\
\hline Intel & $\underline{\text { Curie }}$ & $\begin{array}{l}\text { :ow-powered module that can turn any article (jewelry, clothing, and other } \\
\text { accessories) into smart, wearable devices. Features Intel's Quark SE SoC } \\
\text { chipset, Bluetooth low-energy radio, sensors and battery charger. }\end{array}$ & Evolving \\
\hline $\begin{array}{l}\text { Novartis, Qualcomm } \\
\text { Existence }\end{array}$ & $\underline{2 n e t}$ & $\begin{array}{l}\text { Using cloud-based } 2 \text { net platform to assemble medical tool information and gather } \\
\text { medical device data during clinical trials. }\end{array}$ & Evolving \\
\hline Nudge & $\underline{\text { Nudge }}$ & $\begin{array}{l}\text { Uses proven algorithms to turn a user's wearable data into a detailed picture of } \\
\text { individual health. Syncs with leading apps and devices. }\end{array}$ & Evolving \\
\hline $\begin{array}{c}\text { Quantum Functional } \\
\text { Semiconductor Research } \\
\text { Center }\end{array}$ & $\begin{array}{l}\frac{\text { Conductive carbon }}{\text { nanotube functionalized }} \\
\text { fabric }\end{array}$ & $\begin{array}{l}\text { Highly efficient conductive carbon nanotube functionalized cotton fabrics with } \\
\text { promising applications in wearable electronics and textile materials. }\end{array}$ & Evolving \\
\hline
\end{tabular}


PNNL RTA Monthly Report - January 2015 Appendix A: Technology Summary

\begin{tabular}{|c|c|c|c|}
\hline Company & Technology & Description & Status \\
\hline Safeti & $\frac{\text { Safeti personal security }}{\text { device }}$ & $\begin{array}{l}\text { When activated, device sends a distress message to "personal security } \\
\text { concierge," including specific contacts, with user's location and status. The device } \\
\text { does not require Bluetooth but rather uses } 2 \text {-way GPS communication to allow the } \\
\text { concierge to follow the user. }\end{array}$ & Evolving \\
\hline SkyTraq & $\frac{\frac{\text { Venus828F multi- Global }}{\text { Navigation Satellite System }}}{\text { (GNSS) receiver }}$ & $\begin{array}{l}\text { multi-GNSS receiver module capable of communicating and tracking up to } 28 \\
\text { satellites concurrently. }\end{array}$ & Evolving \\
\hline Stanford University & $\underline{\text { Nanowire Fabric }}$ & $\begin{array}{l}\text { Fabric that can insulate against conduction and convection, prevent loss of } \\
\text { infrared radiation, allow moisture to escape, and even actively heat up with the } \\
\text { help of a battery. }\end{array}$ & Evolving \\
\hline Texas A\&M & GeoTrooper & $\begin{array}{l}\text { A location-aware system that uses an ad-hoc Wi-Fi network to broadcast and } \\
\text { receive GPS coordinates of equipment and/or rendezvous points. The system } \\
\text { consists of beacons, ruggedized computers placed at assembly points that } \\
\text { broadcast their position over Wi-Fi, and receivers, handheld Android devices } \\
\text { which orient the user towards the beacons and/or any predetermined coordinates. }\end{array}$ & Available \\
\hline Venture Heat & $\frac{\text { Wearable Cooling }}{\text { Technology }}$ & $\begin{array}{l}\text { Apparel that reduces moisture and keeps the wearer cool. Features slim built-in } \\
\text { ventilation fans under the arms and honey-combed construction membrane } \\
\text { creates airways that allows flow throughout the entire garment. }\end{array}$ & Evolving \\
\hline Wi2Wi Corporation & $\frac{\text { W2SG0021i miniature }}{\text { GNSS module }}$ & $\begin{array}{l}\text { Miniature GNSS module and high-sensitivity, low-power stand-alone receiver } \\
\text { designed for portable applications. Concurrently tracks multiple satellite } \\
\text { constellations and has fast time-to-first-fix, a small form factor, and high receive } \\
\text { sensitivity. }\end{array}$ & Evolving \\
\hline
\end{tabular}




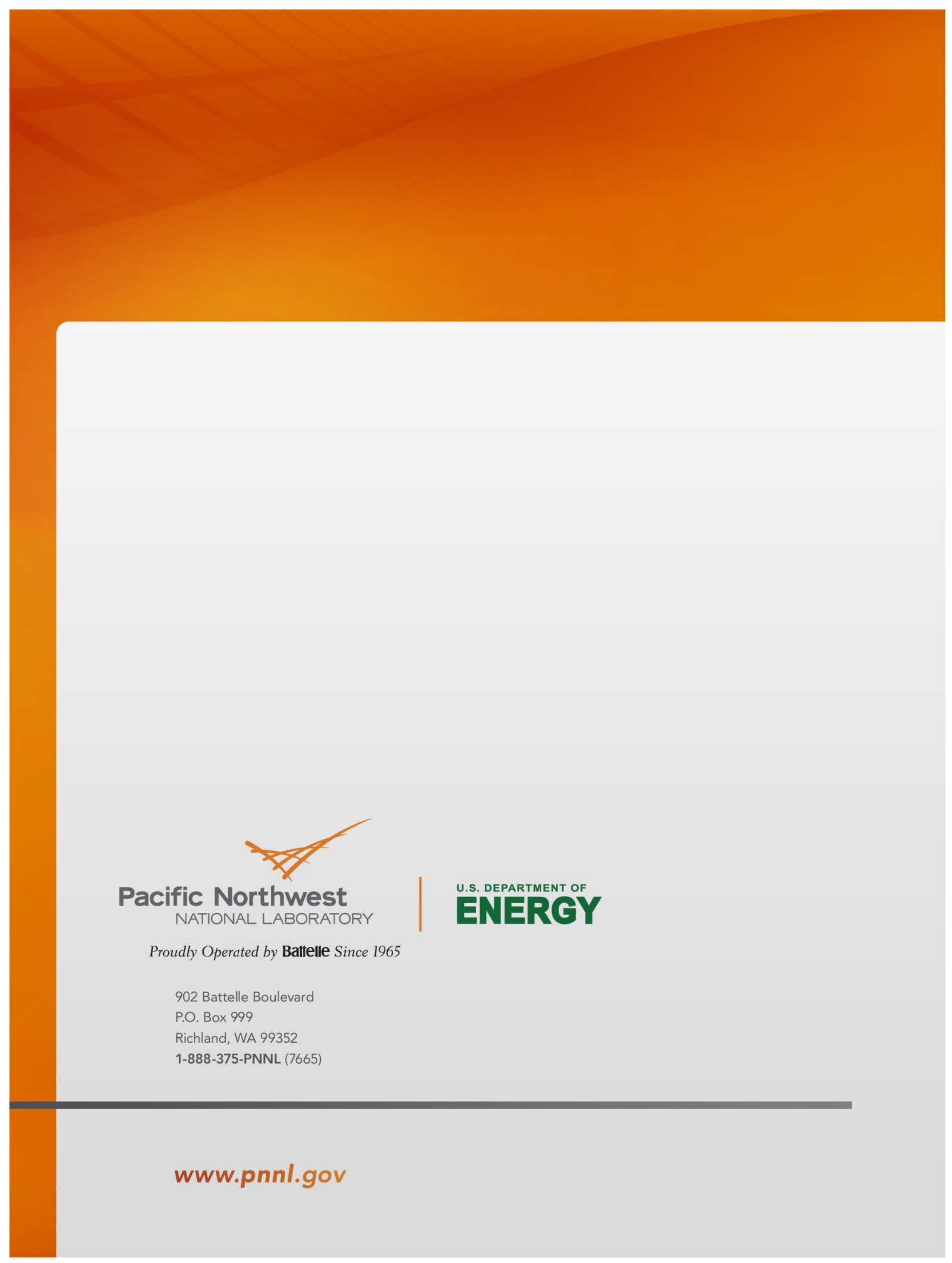

